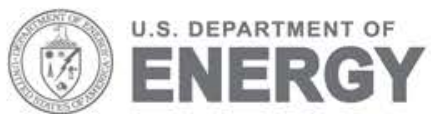

Prepared for the U.S. Department of Energy

Under Contract DE-AC05-76RL01830

\title{
Overview Report: Normal and Emergency Operation Visualization
}

\section{Abridged Summary of a Human Factors/Visualization Research Project on Power Grid Operations}

Frank L. Greitzer, PNNL

May 2011

Pacific Northwest

NATIONAL LABORATORY 


\title{
DISCLAIMER
}

This report was prepared as an account of work sponsored by an agency of the United States Government. Neither the United States Government nor any agency thereof, nor Battelle Memorial Institute, nor any of their employees, makes any warranty, express or implied, or assumes any legal liability or responsibility for the accuracy, completeness, or usefulness of any information, apparatus, product, or process disclosed, or represents that its use would not infringe privately owned rights. Reference herein to any specific commercial product, process, or service by trade name, trademark, manufacturer, or otherwise does not necessarily constitute or imply its endorsement, recommendation, or favoring by the United States Government or any agency thereof, or Battelle Memorial Institute. The views and opinions of authors expressed herein do not necessarily state or reflect those of the United States Government or any agency thereof.

\author{
PACIFIC NORTHWEST NATIONAL LABORATORY \\ operated by \\ BATTELLE \\ for the \\ UNITED STATES DEPARTMENT OF ENERGY \\ under Contract DE-AC05-76RL01830
}

Printed in the United States of America
Available to DOE and DOE contractors from the Office of Scientific and Technical Information,
P.O. Box 62, Oak Ridge, TN 37831-0062;
ph: (865) 576-8401
fax: $(865)$ 576-5728
email: reports@adonis.osti.gov

\begin{abstract}
Available to the public from the National Technical Information Service, U.S. Department of Commerce, 5285 Port Royal Rd., Springfield, VA 22161 ph: (800) 553-6847 fax: $(703) 605-6900$ email: orders@ntis.fedworld.gov online ordering: http://www.ntis.gov/ordering.htm
\end{abstract}

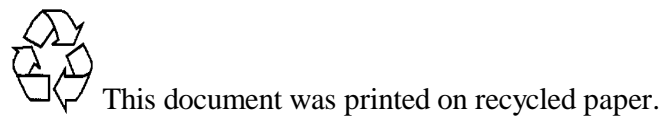




\section{Overview Report: Normal and Emergency Operation Visualization}

FL Greitzer

May 2011

Prepared for the U.S. Department of Energy under Contract DE-AC05-76RL01830

Pacific Northwest National Laboratory

Richland, Washington 99352 


\section{Foreword}

This is an overview report to document and illustrate methods used in a project entitled "Normal and Emergency Operations Visualization" for a utility company, conducted in 2009-2010 timeframe with funding from the utility company and the U.S. Department of Energy. The original final report (about 180 pages) for the project ${ }^{1}$ is not available for distribution; this abridged version contains descriptions of methods and some findings to illustrate the approach used, while avoiding discussion of sensitive or proprietary information. Because this document alludes to findings from the original study (and report) that assessed the design of an operational system, its distribution is limited to research collaborators who may benefit from the discussion of research concepts and methods that were applied in this study.

${ }^{1}$ Greitzer, FL, OA Kuchar, K Huston, \& R Ramanathan. 2009. Normal and Emergency Operation Visualization: Final Report. Richland, WA: Pacific Northwest National Laboratory. 


\section{Table of Contents}

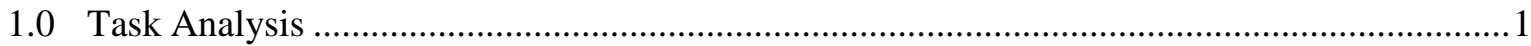

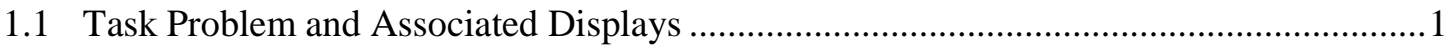

1.2 Knowledge Gained Through Dispatcher Interviews .......................................................... 1

2.0 Overview of Cognitive Task Analysis Results ..........................................................................

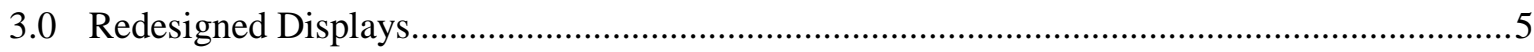

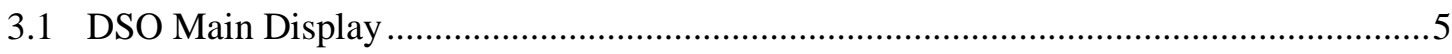

3.1.1 Problems with the Current Display ………......................................................6

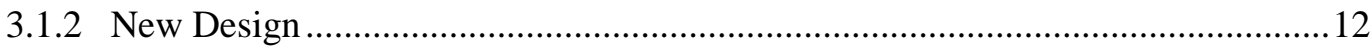

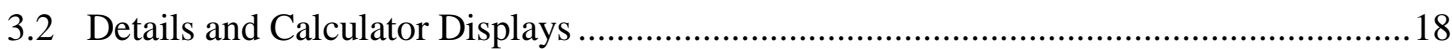

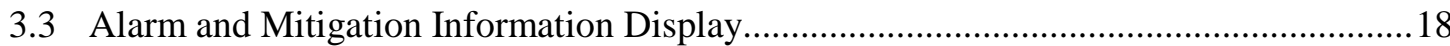

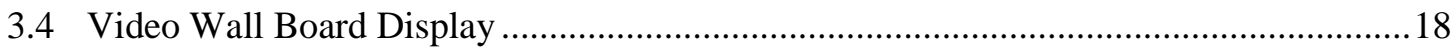

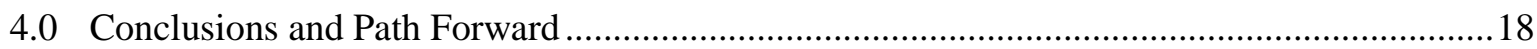

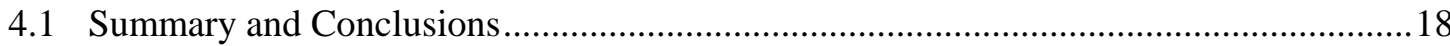

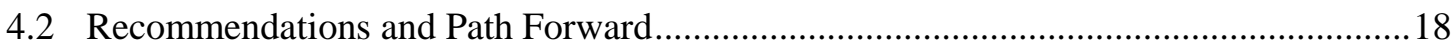

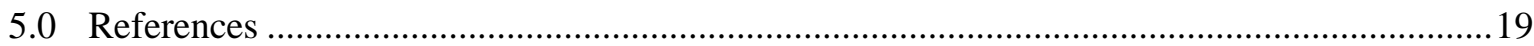

Appendix D: Human Factors Background for Analysis and Redesign of Displays .....................D-1

Appendix L: Report on Problem Selection ...........................................................................

[Other Appendices omitted] 


\section{List of Figures}

Figure 3-1. Comparing (a) Current (this page) and (b) Redesigned Main DSO Display (next

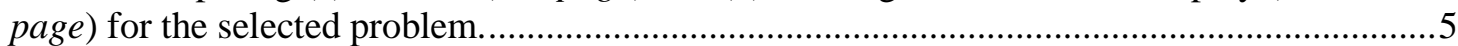

Figure 3-2. Highlighting Important Information in DSO Main Display ........................................

Figure 3-3. Highlighting Secondary Information in DSO Main Display. Information that is not necessary for all emergency situations should be moved to a secondary display.......................9

Figure 3-4. Highlighting Irrelevant Information in DSO Main Display......................................... 10

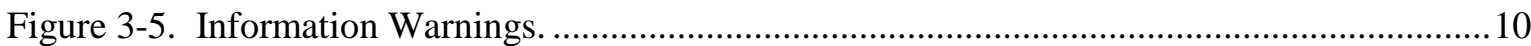

Figure 3-6. DSO Main Display Locations of Dispatcher Entered Data.........................................11

Figure 3-7. Redesigned DSO Main Display. ......................................................................... 12

Figure 3-8. Key Information Located at the Top of the Screen................................................. 13

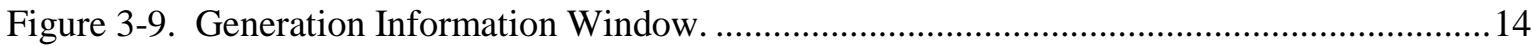

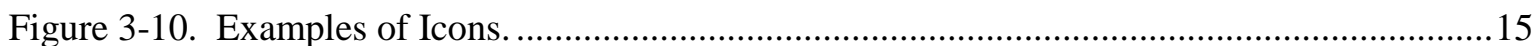

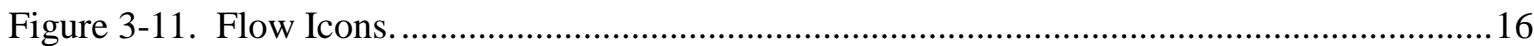

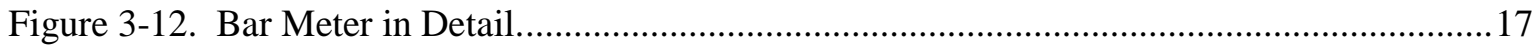

Figure 3-13. Example of a Deductions Pop-up Window. ............................................................... 17 
[This Page Intentionally Blank] 


\section{Executive Summary}

The goal of this project report is to document the PNNL team's findings in conducting a detailed analysis and design project in support of CLIENT operational decision making and associated normal and emergency operations displays and visualizations. The work comprised a series of phased tasks, including:

1. Selection of a representative problem.

2. Conducting analysis of displays, visualizations, and decision processes.

3. Identifying deficiencies of the current displays and interactions for the selected problem.

4. Design of improved displays and visualizations to address the deficiencies.

5. Development of prototypes incorporating these designs within the CLIENT operational EMS environment and vetting the proposed designs with operators and management.

Findings and recommendations are summarized at a high level as follows:

\section{Problem Selection}

An analysis involving input from CLIENT managers and operators led to the selection of a specific problem (Loss of a single element on a single path, here referred to as "Loss of Element problem") as the subject of the study. This problem was selected from a list of potential problems generated by the study team that included PNNL researchers and CLIENT managers and operators. The method used to select the problem is described in a separate summary document. This problem was among the more difficult events from an information processing perspective (but not the most difficult, as the loss of multiple elements and multiple paths would constitute the most difficult problems). The loss of element problem was deemed the best focus for our study because it represents a critical issue by itself, and addressing display/visualization needs for this problem will likely produce conclusions and recommendations that apply to many other problems.

\section{Analysis Approach}

The methodology used in the analysis phase of this work is based on a theoretical framework that guides the process and that provides a rationale for decisions about design deficiencies and recommendations for displays to improve operator performance. This rigorous and systematic approach is in stark contrast to less-sophisticated (and more ad-hoc) design approaches that may lead to complicated and convoluted displays and processes that increase the workload of operational decision makers and fail to provide adequate situation awareness. The framework of naturalistic decision making, concepts of situation awareness, and an associated cognitive task analysis methodology serve as the foundation of the approach employed in the analysis, and these concepts were in turn applied in the employment of an expert operator decision model that was adapted specifically by PNNL for power grid operations. Highlights of the approach included interviews with experienced dispatchers, analysis of Dispatcher Standing Orders, and associated cognitive task analyses.

\section{Findings and Recommendations}

All alarms (more than a dozen) associated with the Loss of Element problem were examined in depth and specific deficiencies were noted for displays and processes associated with individual alarms. At a higher level, conclusions were drawn about design deficiencies in each of the current displays associated with this problem, as well as suggested improvements to these displays. Improvements addressed the content, organization, and visualization concepts (e.g., improved visualizations for line/path status or MVAR status) for the associated displays. Recommendations addressed more effective use of color, icons, and general look-and-feel, in accordance with best practices for graphical user interface design. At a deeper (cognitive and decision making) level, the analysis included specific recommendations for display content 
and organization to provide more efficient access to information to support decision making. The analysis also led to recommendations for new displays to support specific decisions and response options, as well as preliminary recommendations for more effective utilization of a video wall display.

Based on the recommendations, prototype displays were implemented for use in the CLIENT control center and training center. It was expected that these prototype displays would be tried out during a "breaking in" period enabling operators to become familiar with the new displays, offering an opportunity to make some tweaks to the designs for improved usability and effectiveness based on user feedback.

The methods and displays designs employed for the selected problem translate readily to other CLIENT applications/events, so that the CLIENT may opt to use the design solutions for the selected problem as a model or standard by which to inform development of displays for other problems. 



\subsection{Task Analysis}

Task analysis is the process of examining and describing specific activities that a user must perform to carry out a function. The steps for doing tasks analysis are:

- Define the purpose of the system and identify required data.

- Gather information about the task.

- Summarize/describe and analyze the task data.

In this project, the users are senior dispatchers and the function is to decide what action needs to be performed when a loss of element occurs. Our approach to task analysis employs a cognitive/information processing orientation that is informed by concepts of naturalistic decision making (Klein, 1993) and a cognitive task analysis (CTA) methodology (Gordon \& Gill, 1997), most recently described for power grid decision making by Greitzer et al. (2009). These are described in more detail in Appendix D. The remainder of this section describes the CTAs that were performed, with specific attention to the task problem, the task displays, and the interviewing process.

\subsection{Task Problem and Associated Displays}

When dispatchers have a problem on the electric network, such as a loss of element, the CLIENT has provided operational protocols called Dispatchers' Standing Orders (DSOs) to aid dispatchers during their problem-solving state. A DSO defines the actions dispatchers will initiate and the responsive actions generators must implement to modify plant output to maintain reliable operation of the transmission system.

[Detailed descriptions of DSOs and associated displays, associated alarms have been omitted]

\subsection{Knowledge Gained Through Dispatcher Interviews}

The team studied the DSO documentation and created a flowchart of the operational protocols for each of the alarms. The flowcharts proved very useful in understanding the procedures that are otherwise only described in the text-based DSO document. A recommendation that is unrelated to the current effort is to incorporate such graphical descriptions of procedures into the standing orders to help operators quickly see the process flow.

The types of information that the PNNL CTA team sought in reviewing documentation and interviewing dispatcher personnel included ${ }^{1}$ :

- Hierarchical relationships - tasks broken down into subtasks.

- Information flow - communication between people.

- Task sequence - order of tasks.

- Environment in which activities are performed.

\footnotetext{
${ }^{1}$ While specifics of this discussion concern the loss of element problem, the underlying CTA process is very general and would apply to all other analyses of operational displays, processes, and operator-system interactions.
} 
The DSO documentation and the flowcharts allowed the team to extract information related to the first three items. The DSO procedure outlines the process of breaking down the loss of element problem into sub-problems, each of which has an order or sequence of tasks that the dispatcher must perform. In these tasks, certain displays are cited that helped the team understand which visualizations were being used to address each alarm. The DSO documentation also indicates whom a dispatcher needs to contact, but it does not necessarily provide insight about the specific data are required for the dispatcher to determine the nature of the problem ${ }^{2}$ and which actions would solve the problem. ${ }^{3}$ This information is "in the mind" of the dispatcher - cognitive scientists refer to this as "tacit knowledge." We conducted interviews with dispatchers to document this tacit knowledge.

To support the interview process, the PNNL CTA team constructed a list of questions for each alarm, aimed at understanding the data that are important in each situation ${ }^{4}$. Once the team finalized the questions, arrangements were made for individual and group interviews with experienced dispatchers who were made available by CLIENT management. Such interviews often had to be scheduled up to a month in advance due to the dispatcher schedules. The interviews addressed each alarm in detail, including identifying the data that dispatchers needed, the displays that the dispatchers use, and any problems or "bottlenecks" that dispatchers could report from their years of experience in the Operations Center. The results of the CTA documentation review and dispatcher interviews are provided in the next section.

\footnotetext{
2 This understanding by the operator is often referred to as "situation assessment" and is described by Endlsey (1997) as "Level 2 SA." For more information see Appendix.

${ }^{3}$ Recognizing which action(s) will solve the problem is an example of "Level 3 SA" and represents a high level of proficiency that is captured in the Operator Decision Model. For more information see Appendix.

${ }^{4}$ This information comprises knowledge represented as mental models and their constituent elements such as cues, patterns, and "stories" used to gain SA and identify likely solutions. For more information see Appendix.
} 


\subsection{Overview of Cognitive Task Analysis Results}

In several visits to the Operations Center, the team interviewed senior dispatchers in relation to the loss of element problem and to observe the dispatchers in the Operations Center. A preliminary set of display designs was developed from these CTA activities, after which some screen prototypes were developed. During the prototyping process, additional visits to CLIENT facility by the CTA team took place to obtain ongoing feedback and inform incremental improvements to the new displays and visualizations that came out of the analysis. This section describes the details and findings of the CTA to document and provide a basis for the recommended design enhancements.

[Detailed documentation of display design issues for all displays associated with all alarms for the selected problem have been omitted. The following is a general list of findings regarding information, actions, display implications extracted from the CTA interviews and observations aggregated over all displays.]

The senior dispatchers commented on other information that is important when using the displays to work the Loss of Element problem:

- Equivalent units are actionable by the senior dispatcher and thus need to be on the display. Knowing if additional units can be brought online would be helpful for SA problem-solving.

- Violation timer calibration. Timer violation needs to start when the alarm is received, not when limits are being changed. Usually, when an unplanned equipment outage is triggering a violation, the violation timer should be started. Since it is not obvious that an unplanned equipment outage is affecting the limits, the senior dispatcher needs to study the situation and then evaluate a course of action (such as assigning limits), which usually takes about $40-50 \%$ of the overall violation time. If you know what the actual violation time is, then this may determine your course of action (for example, determine if you have enough time to bring on additional units).

- Tell/show us what is wrong. Use the large video wall display to show current status, especially when there is a problem. The video wall display can be configured and designed to show what is wrong and to lead dispatchers to the most appropriate information. Once an event has occurred, the dispatchers will not be using the large wall display.

- All applicable tools/displays should be coordinated to show mitigation options. It would be preferred that all the tools be brought together to deal with this issue and that all mitigation options be displayed to the senior dispatcher:

o Can a counter-schedule be used?

o Is there room to circulate power?

o Can you curtail schedules and what kind of curtailment is needed?

- Provide better display support to enhance SA. The senior dispatchers want an overhead display so that they can easily keep track of critical and developing problems so that sanctionable alarms can be avoided.

- Relocate necessary data to appropriate display. For counter-scheduling, the senior dispatcher needs to navigate to the Controller Total Change display and look for a particular value in the mid-right of the display. This one value needs to be migrated to the DSO 306 display. All other actions require a phone call.

- Display unused capacity. Need to see unused capacity.

- Display estimated required curtailments. Senior dispatchers want to see how much to curtail (estimates) automatically from the system to get under the limit, and if put into place, how much are we under the limit

- Display mitigation options. The senior dispatchers noted that displaying mitigation options would be beneficial. 
- Too much information. Most displays contain more information than is required to work the problem, and the supplementary information is either irrelevant or distracting. Suggestion is to include only the information that is required for the decision at hand; other information may be relegated to supporting displays. An example concerns support for curtailment options: if the minimum reactive reserves cannot be maintained and a curtailment is needed, the senior dispatchers wanted to have different options calculated automatically to show the effect of each option.

- Display related environmental information to increase SA. Possible environmental information to display and provide greater SA are:

o Areas involving fire overlaid on power line display

o Lightning strikes areas overlaid on the power lines display.

o Weather conditions overlaid on power lines display. The weather is particularly important in the winter months, when dealing with freezing lines.

- New tools for forecasting. When a senior dispatcher needs to plan ahead (such as setting limits), knowing schedules, trends, outages, and having an idea of where the system might be in the next hour would be very useful. Another tool could provide historical information (what is the current situation, what was it like yesterday around the same time, what was it like a year ago around the same time)

Example finding from the analysis of location/availability of necessary information for working the problem: Table 2-1 shows the location of the information needed by the dispatchers when dealing with an Operating Transfer Capability (OTC) Alarm for the selected Loss of Element problem. An OTC alarm reflects a condition in which the system is congested and operating outside of its safe/reliable conditions, which is defined by an industry threshold OTC value.

Table 2-1. Sanctionable Alarm Information and Distance Calculations

\begin{tabular}{||l|c|c|c||}
\hline \multicolumn{1}{|c|}{ Information Needed } & $\begin{array}{c}\text { Information } \\
\text { Available? }\end{array}$ & $\begin{array}{c}\text { Navigation Required to } \\
\text { Access Information? }\end{array}$ & $\begin{array}{c}\text { Design Change } \\
\text { Needed? }\end{array}$ \\
\hline \hline OTC value & Yes & $\begin{array}{c}\text { Navigate to Alarm Summary } \\
\text { display }\end{array}$ & Yes \\
\hline Actual/Schedule limit & Yes & None (on current display) & No \\
\hline Value over limit & No & -- & Yes \\
\hline Deductions affecting limit & Yes & $\begin{array}{c}\text { Navigate to Transfers Details } \\
\text { display; scrolling required }\end{array}$ & Yes \\
\hline Reasons for deductions & No & -- & Yes \\
\hline Choices & No & -- & Yes \\
\hline Mitigation Affect & No & -- & Yes \\
\hline Actual Violation Time & No & Yes \\
\hline System Frequency & Yes & Only available on Wall display & Yes \\
\hline
\end{tabular}




\subsection{Redesigned Displays}

The focus of our analysis was the primary set of displays associated with the Loss of Element event. In this section we describe each of the new display designs and the associated design rationale.

[Detailed descriptions of each of the redesigned displays and associated rationale have been omitted. One example is provided; contents of displays are purposely blurred]

\subsection{DSO Main Display}

When faced with a loss of element, the dispatcher uses the appropriate DSO operational protocol in conjunction with the associated display. The purpose of the DSO is to prevent voltage collapse internal to the system that could result in cascading line outages impacting the broader interconnected systems. Due to its importance, our main focus was the redesign for the main DSO display. We concluded that a complete redesign was required to support dispatchers in their task. Figure 3-1 depicts both the current display (a) and the redesigned display (b).

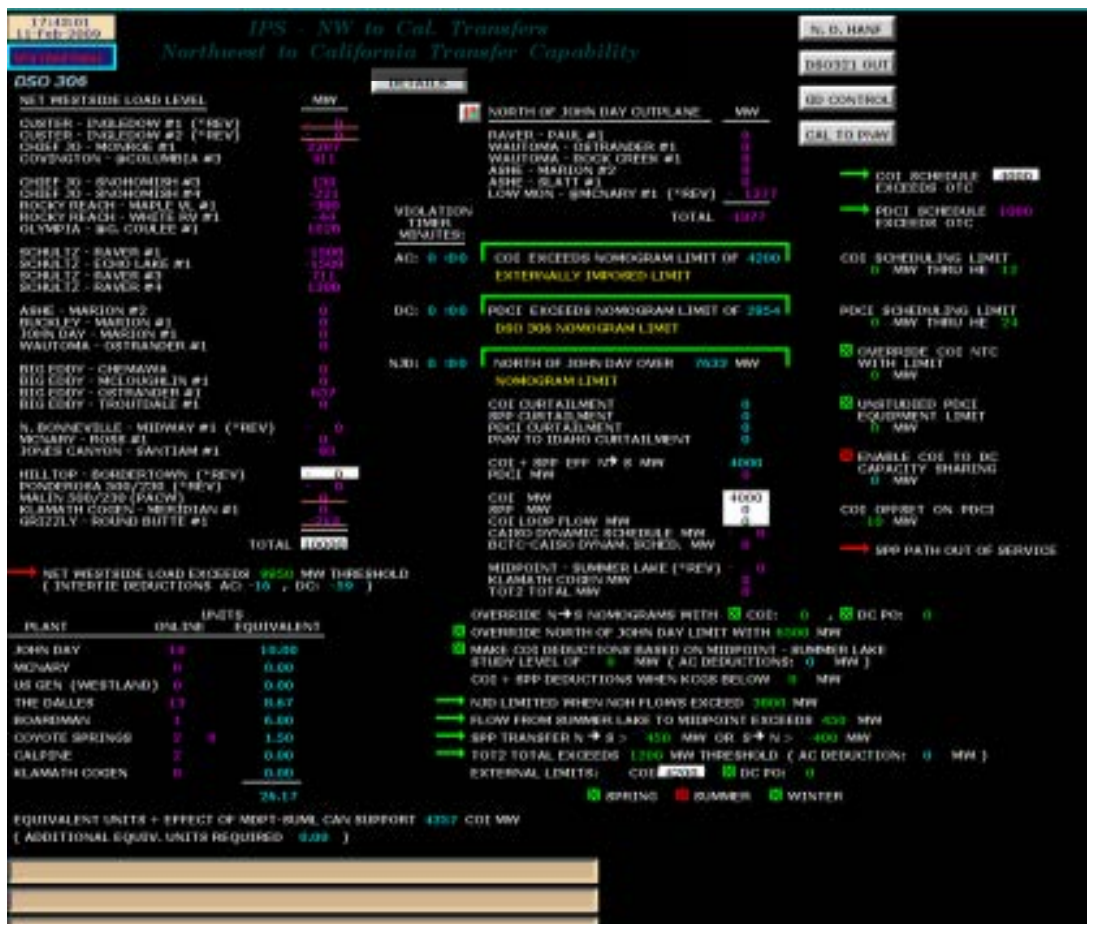

(a) Current DSO Main Display

Figure 3-1. Comparing (a) Current (this page) and (b) Redesigned Main DSO Display (next page) for the selected problem. 


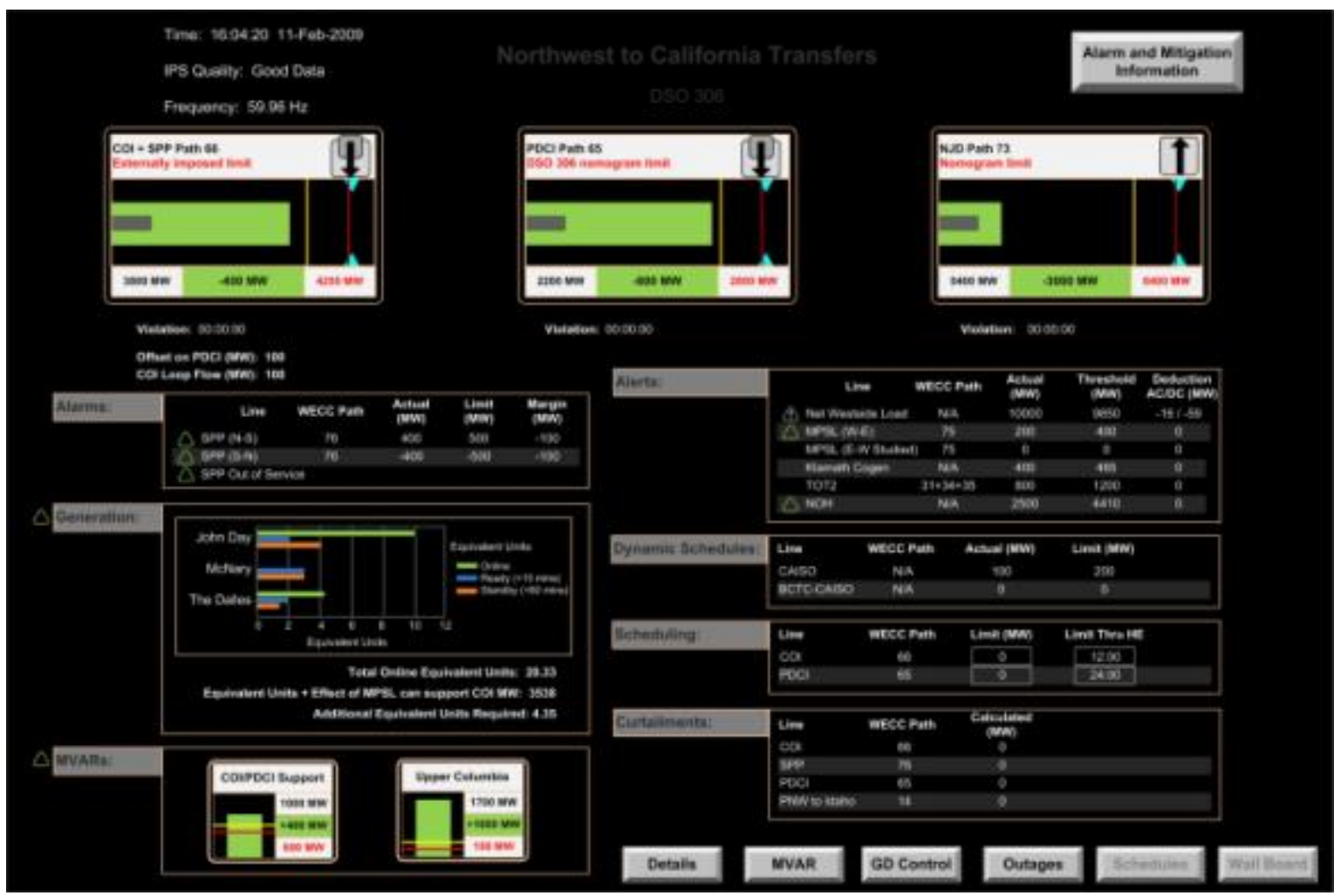

(b) Redesigned DSO Main Display

Figure 3-1. (Cont'd) Comparing (a) Current and (b) Redesigned Main DSO Display for the selected problem.

\subsubsection{Problems with the Current Display}

This section outlines design problems with the DSO display currently used by CLIENT dispatchers. Issues include text font and size, color usage, and organization and placement of information.

\section{Text Font and Size}

The current text font is "Times New Roman" and the size is 12 point. As noted in Appendix D, the Times font was first developed so that more characters could fit into one printed line of text; thus, the characters are very close together (such as the printing in this document). 12 point is the minimum size that can be used for a dispatcher to easily read the information on the screen.

Overall, the current display has a lot of text that the dispatcher needs to scan or read. All the words on the screen are in capital letters, which may be a throwback to earlier teletypes and video display monitors with limited font design features. Research has shown that text in ALL CAPS is more difficult to read than standard upper/lower case letters.

\section{Color}


Color has a major impact on human-computer interaction - effects can be positive or negative. According to Murch (1984) "Color can be a powerful tool to improve the usefulness of an information display in a wide variety of areas if color is used properly. Conversely, the inappropriate use of color can seriously reduce the functionality of a display system" (Taylor and Murch, 1986). Color is a major component in GUIs. Appropriate color use can aid user memory and facilitate the formation of effective mental models. As Murch (1984) noted, the effective use of color can be a powerful tool; however, ineffective use of color can degrade an application's performance and lessen user satisfaction. And use of too many colors may degrade operator performance due to increased difficulty in keeping track of the meaning of the colors.

The current DSO display uses at least 8 colors (blue, white, magenta, red, yellow, dark yellow, gray, cyan, salmon), including reverse video and motion in conjunction with these colors. This may be at an upper limit to working memory capacity (e.g., Miller, 1956). Of even more concern, the same color was used on the display to represent different information. For example, cyan was used for the title, the violation timers, and equivalent unit calculations. In the SCADA user's guide (online documentation), cyan is used to indicate "value is good". Also, colors are not used consistently across the dispatcher's displays. For example, cyan in the alarm list display means "information only" (such as time changes, disk warnings, etc) and is the lowest priority alarm. Yet, cyan is used to show that violation timers are of high priority in the DSO display since violations are sanctionable.

The DSO 306 display uses a great deal of the color green, which in North American culture tends to be interpreted as "all is well." The dominance of the color green may make it difficult to notice alarms: for example, notice that the display in Figure 3-1 (a) is alarming, but green is the dominant color. The SCADA User's Guide itself is partly responsible for this problem: it says that green should be used to indicate that a value can be modified by the dispatcher.

\section{Information Groupings}

This section describes issues of information grouping with the current DSO display.

First, the DSO display presents a great deal of information and appears quite cluttered. With training, one can learn where to find relevant information, but grouping similar items together and placing important information in an ideal location would decrease cognitive load.

One of the outcomes of our dispatcher interviews was a list of required items for understanding sanctionable events. Figure 3-2 depicts where needed information is currently located on the DSO display. 


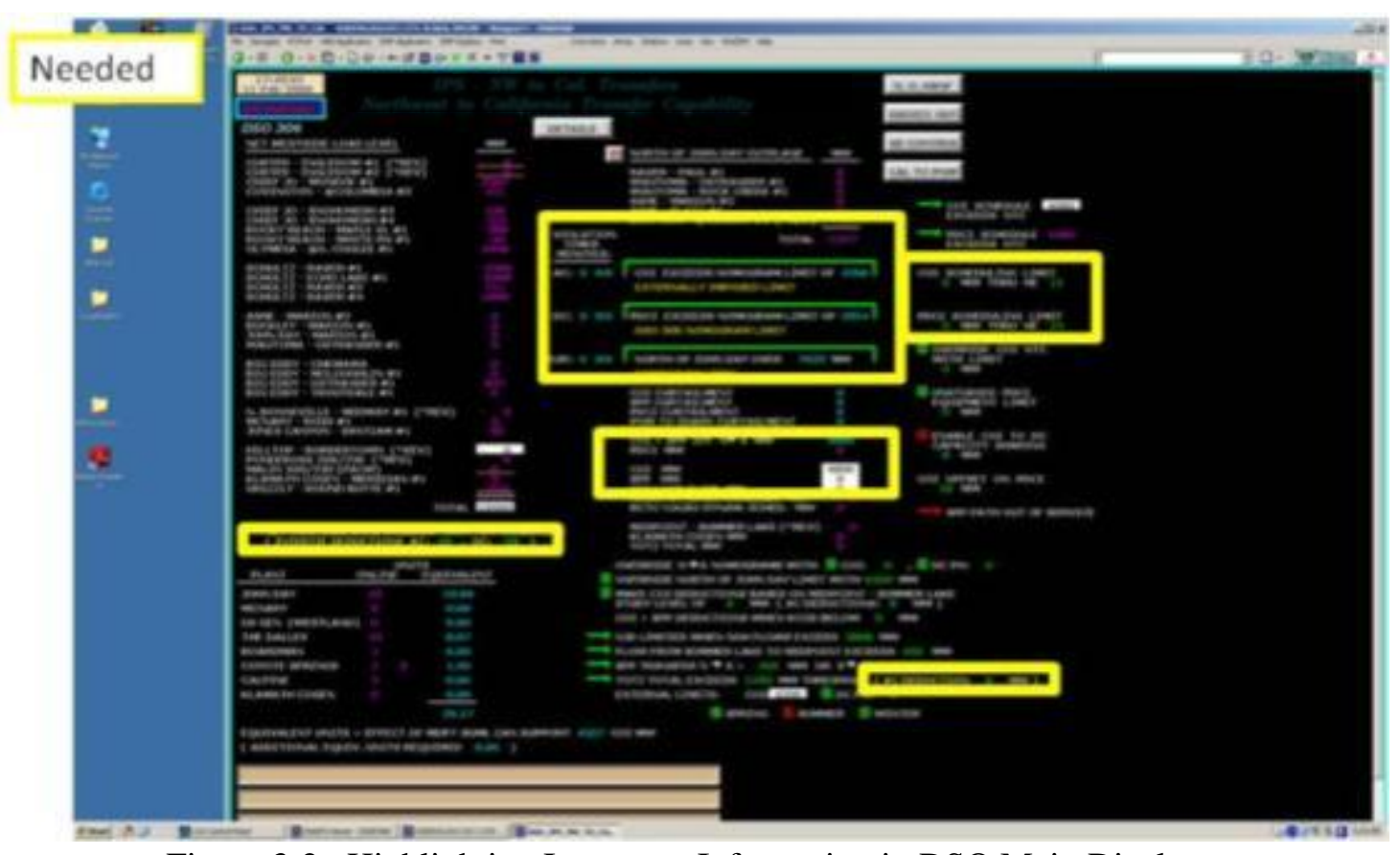

Figure 3-2. Highlighting Important Information in DSO Main Display.

The yellow boxes highlight the location of the following items:

- Sanctionable alarm (top middle column) that contains the violation timer, which path alarmed and why, and the OTC value.

- Current path flows (lower box in the middle column).

- Imposed scheduling limit (last column).

- IPS deductions (remaining box areas)

The violation timers on this page are only started when a dispatcher starts to take action by changing/inputting values on the DSO display; thus, the violation timers do not show actual violation time from beginning of the event.

When dealing with sanctionable events, the dispatchers also need the following pieces of information: marginal flow values for each path; and the system frequency. It can be seen that the information is not grouped together and it is not consistently located on the screen for ease of access.

Second, much of the information on the DSO display is not required all of the time. Figure 3-3 depicts information that is secondary in terms of task flow. 


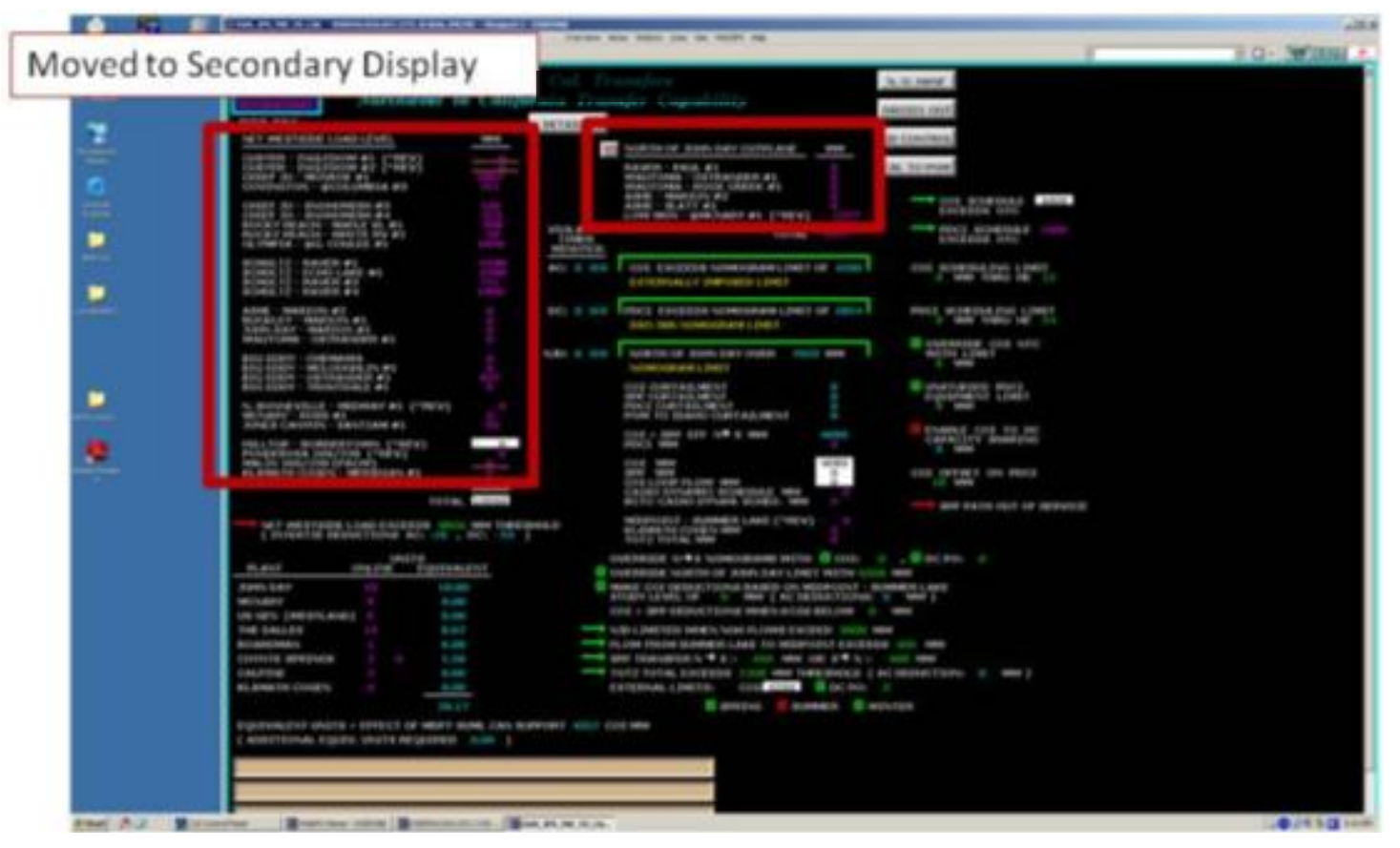

Figure 3-3. Highlighting Secondary Information in DSO Main Display. Information that is not necessary for all emergency situations should be moved to a secondary display.

We note that this secondary information is located at a prime display location. Humans read and process information from left to right, top to bottom. The secondary information is placed in a position that is typically used for information that is deemed very important and is needed all the time (top of screen, left to right). This placement of secondary information causes more cognitive overhead when solving problems since the mind must "process and delete" before looking for other (more relevant) information to the problem at hand.

Third, the DSO display has a large amount of data, not all of which are relevant to the dispatcher's task. For example, generation information is found in the lower left corner of the DSO display, as depicted by the red box in Figure 3-4. The dispatchers need to know plant generation, but only three plants are directly related to the DSO and which dispatchers have some control over (i.e., the dispatcher can call the plant and request more generation or less generation). Space realty is very important when needed to present information to the user; only providing relevant information supports a better cognitive workflow and does not occupy the eyes and mind with irrelevant information. In addition, when dispatchers need to deal with an equivalent units alarm, not all required information is presented.

During our interviews, the dispatchers indicated that they would like to see the following information: how many units online; how many are offline but are ready; and how many units are offline but may take more than 10 minutes to start generating. The current DSO display only gave the number of units online and if the dispatcher wanted more information, he or she would need to call each plant. This is very time consuming when dealing with an alarm. 


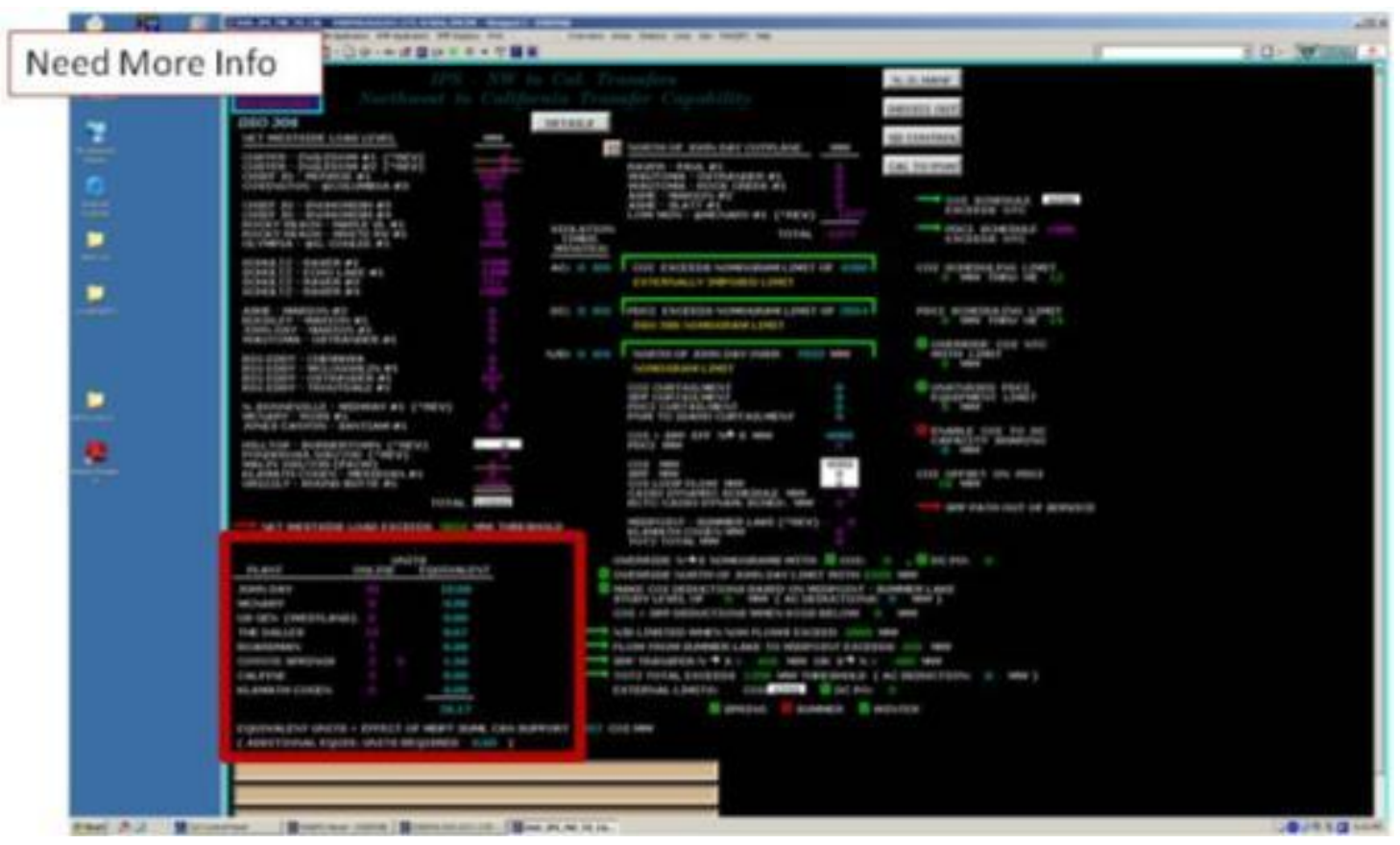

Figure 3-4. Highlighting Irrelevant Information in DSO Main Display.

Fourth, the DSO display contains alarming information as indicated by either a 3-sided box or an arrow. Figure 3-5 depicts examples of the latter.

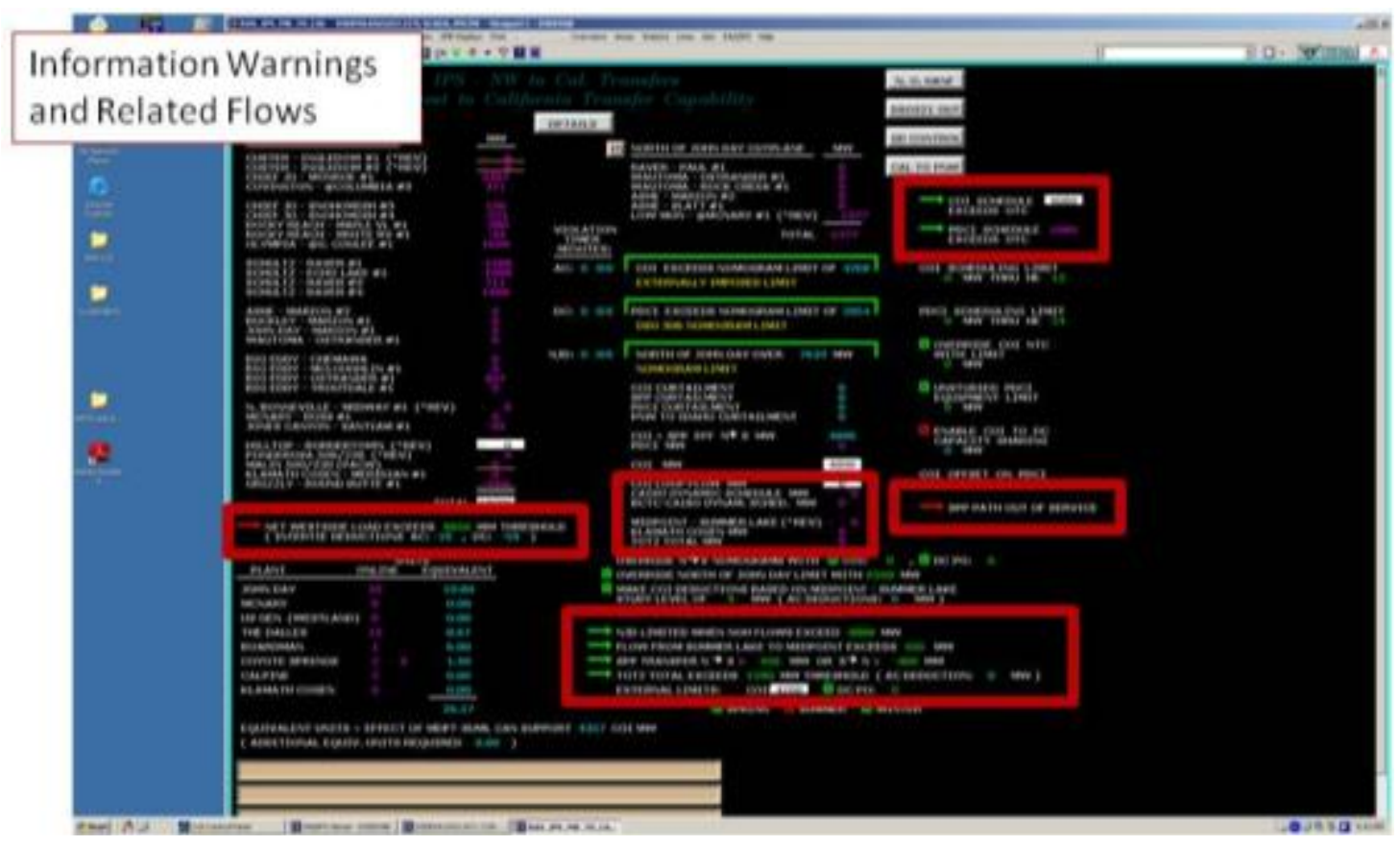

Figure 3-5. Information Warnings.

A closer scrutiny of the current DSO display reveals that information warnings are scattered about the display. Information associated with these warnings (such as the red box in the middle column, first from 
top) is also not grouped with the path warnings themselves. This causes much cognitive overhead to search the display to find relevant information for the alarm.

Fifth, a basic user interface design requirement is that the display functionality must be clear, concise, and represented well. The current DSO display has two functions: provide information to the dispatchers; and allow dispatchers to make real-time changes to the system. Figure 3-6 depicts some of the areas in which dispatchers are allowed to manually arm and enter data.

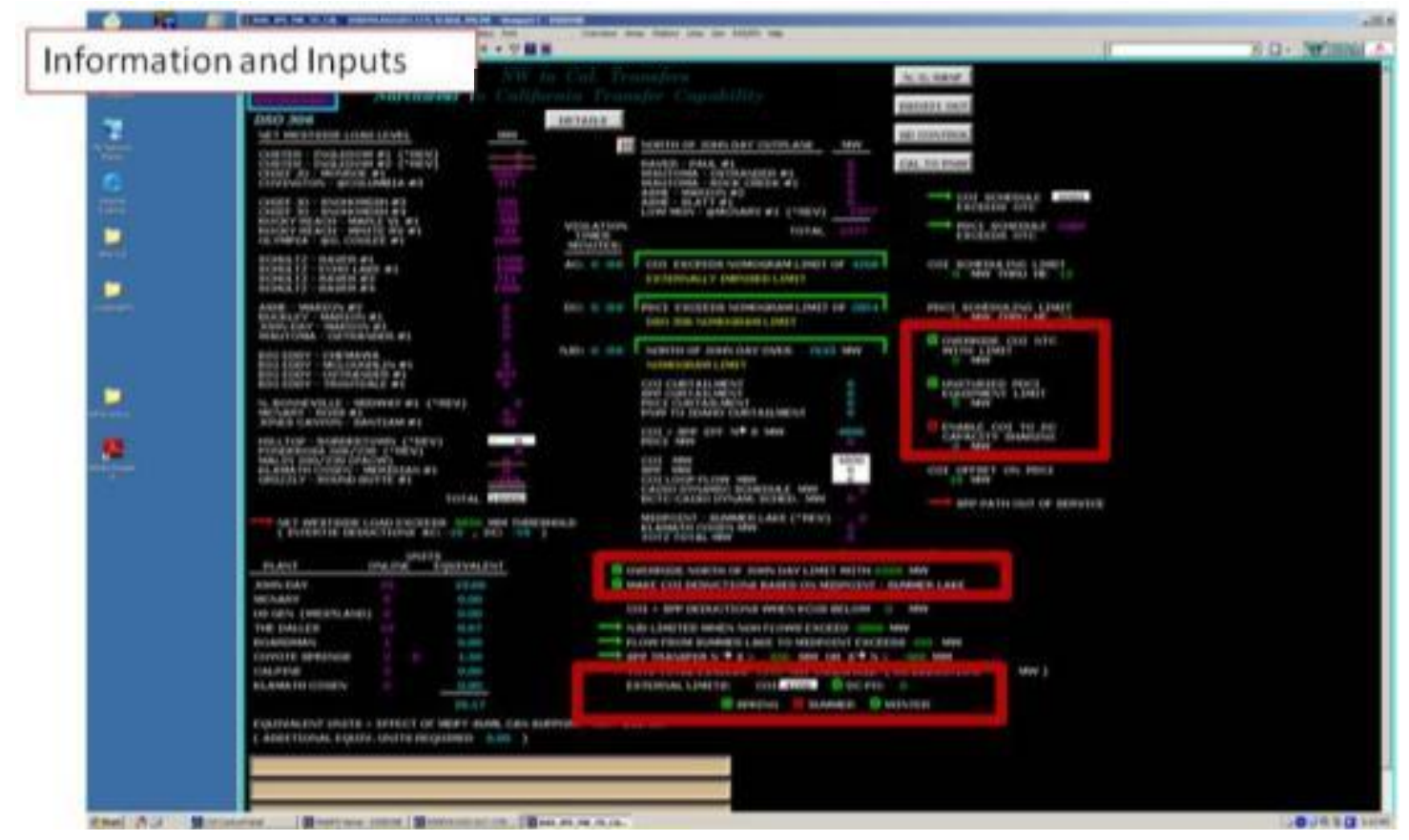

Figure 3-6. DSO Main Display Locations of Dispatcher Entered Data.

Clearly, again, this information is not grouped effectively. Moreover, the main issue is how the dispatchers calculate the values. The current procedure requires the dispatchers to open the details transfer display related to the DSO and arm the calculator. Once the dispatcher configures the calculator, these values are then manually transcribed back into the DSO display-a time consuming activity that invites human error.

Sixth, some information is obscured by the clutter while other information is simply unavailable on the display. For example, when current path flow exceeds the OTC, curtailment calculations are done automatically by the system. These values are of importance when dealing with a sanctionable alarm, yet they are located in the middle of the second column on the current DSO display. In the case of an alarm indicating inadequate MVARs on the path, the information required to address the problem is not found on the current display, nor is there a button to take the user to the information.

Finally, there is an issue with the placement of the buttons on the DSO display. Most of the buttons are located in the upper right corner of the display, except for the "Details" button located under the title. The placement of the buttons does not follow user interface design conventions and standards; usually buttons are grouped and located in the lower right portion of the display. 


\subsubsection{New Design}

[Details on proposed new designs for each of the DSO displays associated with the various alarms for the selected problem have been omitted from this overview report. Only one example is provided here and contents of displays are purposely blurred]

Figure 3-7 provides an illustrative example of the proposed display design for this problem.

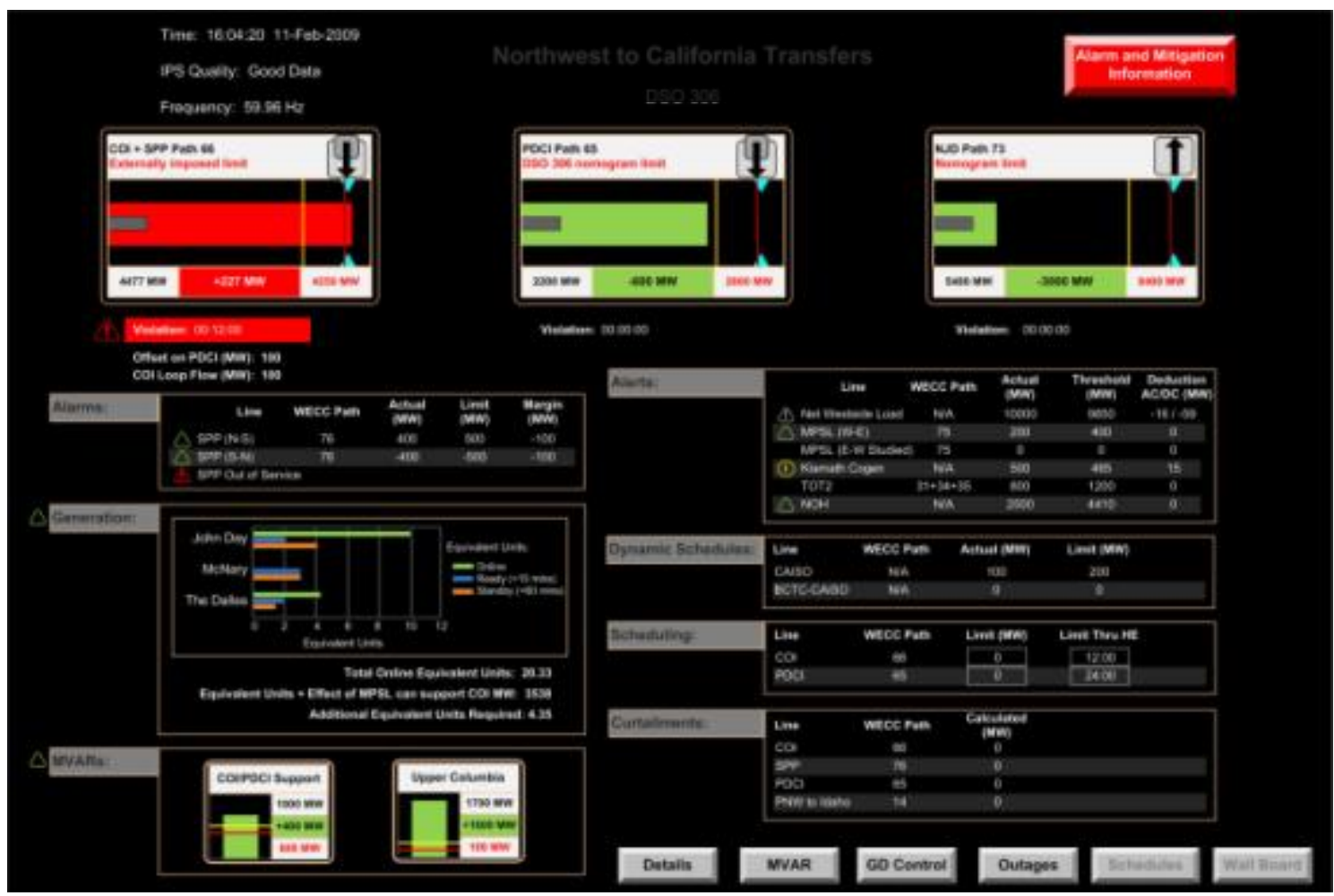

Figure 3-7. Redesigned DSO Main Display.

An immediately obvious difference with the new display is the use of graphics to portray important information and grouping similar information together. This is design follows user interface guidelines and principles. For example, the design is simple and well-organized - a two-column layout with the main focus area at the top. All generation information and generation support is located in the left column, with specific paths/line support located in the right column.

The information is grouped into categories with titles that are familiar to the dispatchers. These categories can be easily seen and scanned. The design is robust and extendable. Currently, all required information can be easily displayed in "tabbed" areas; however, as technology improves and more information is gathered that needs to be displayed, the "tabbed" format can be extended with ease and can become a truly tabbed pane, allowing more space for the new information.

The use of color has been simplified and more optimized on the new display. One of the most important elements in using color effectively is knowing the user, the user's environment, and the task the user is performing. Color should be used to emphasize information; it should be used sparingly and consistently. We have applied the following conventions for use of colors on these displays: 
- Red - attention required. Dispatcher needs to be aware of the value/situation. Action required.

- Yellow - caution state. No immediate action is required.

- Green - normal (good) state. No action required.

- Blue - standby or reserve state. Background information.

- Magenta - bad telemetry data information. No action required but validity of shown data must be taken into account during decision-making strategies.

- White - informational text.

- Dark gray - background color for grouping tabbed information.

These carefully chosen colors help the user easily recognize problems and encourage users to develop a good mental model.

The highly important information depicted by the dispatchers consists of the following:

- For a given path, need to know the current flow, the OTC value, and the margin between these values.

- For a given path that is scheduled, scheduling information is needed.

- Deductions affect the limit and reasons for the deductions.

- Actual Violation Time.

- System Frequency.

- Provide a set of strategies for a given alarm.

- Provide mitigation effect.

All of these pieces of important information are immediately visible at the top of the redesigned display, as depicted by the yellow box in Figure 3-8.

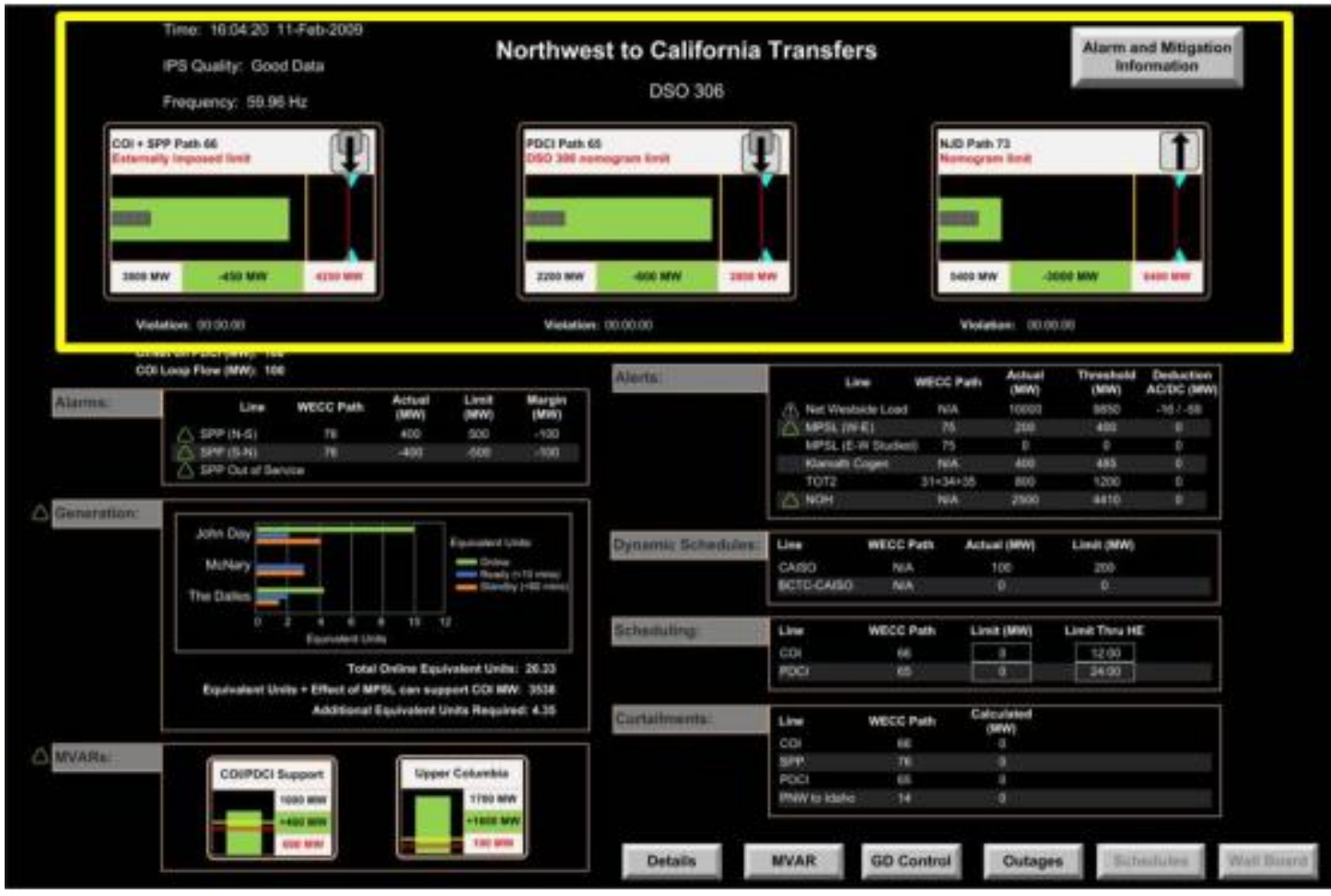

Figure 3-8. Key Information Located at the Top of the Screen. 
The DSO 306 protocol document states: "Its purpose is to prevent voltage collapse internal to the Northwest system that could result in cascading line outages impacting the Western Electricity Coordinating Council (WECC) system. This is a problem during heavy North to South (N-S) transmission loading across the North of John Day (NJD) cut-plane and heavy export conditions on the COI/NW-Sierra and PDCI." On the redesigned display, the COI/NW-Sierra (COI + SPP), PDCI, and NJD paths are emphasized. The information included in these bar meters (a close-up of a bar meter is depicted in Figure 3-12) contains the first four bullets mentioned as highly important information. The remaining items are also located in the top part of the display, with frequency being and an "Alarm and Mitigation Strategies" button on the right.

In addition to emphasizing and grouping relevant information, some information was streamlined or removed to secondary displays. For example, in the Equivalent Units tabbed pane, only the generation plants that the dispatchers control are shown. If the dispatchers need to see the remaining plants, they can click on the Equivalent Units area to yield a pop-up display as depicted in Figure 3-9.

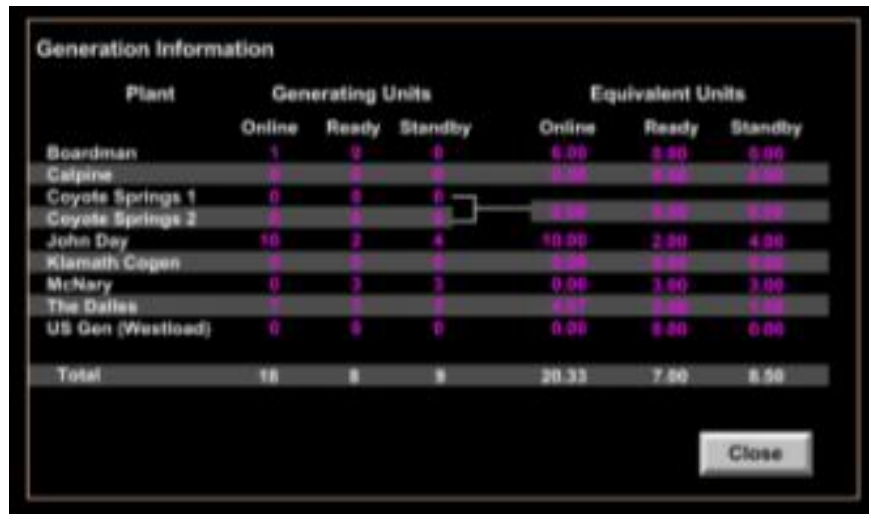

Figure 3-9. Generation Information Window.

We also added information that the dispatchers deemed as important; in addition to showing how many units are online, the display also shows how many units are ready (can be brought online within 10 minutes or less) and in standby (can be brought online within 60 minutes or less, but more than 10 minutes).

Along with generation, dispatchers stated a need to know about the two reactive reserves that are associated with this DSO. This information was brought forward graphically to help dispatchers know what their reserves are in case of emergencies and to notify them if their reserves are below required levels.

Our analysis showed that some alarm states require different levels of action by dispatchers. To help distinguish these, we simplified the display and developed new icons for two levels of alarm (warning level and information-only), as shown below.

Warning icon:

Information-only icon:

Examples are depicted in Figure 3-10. 


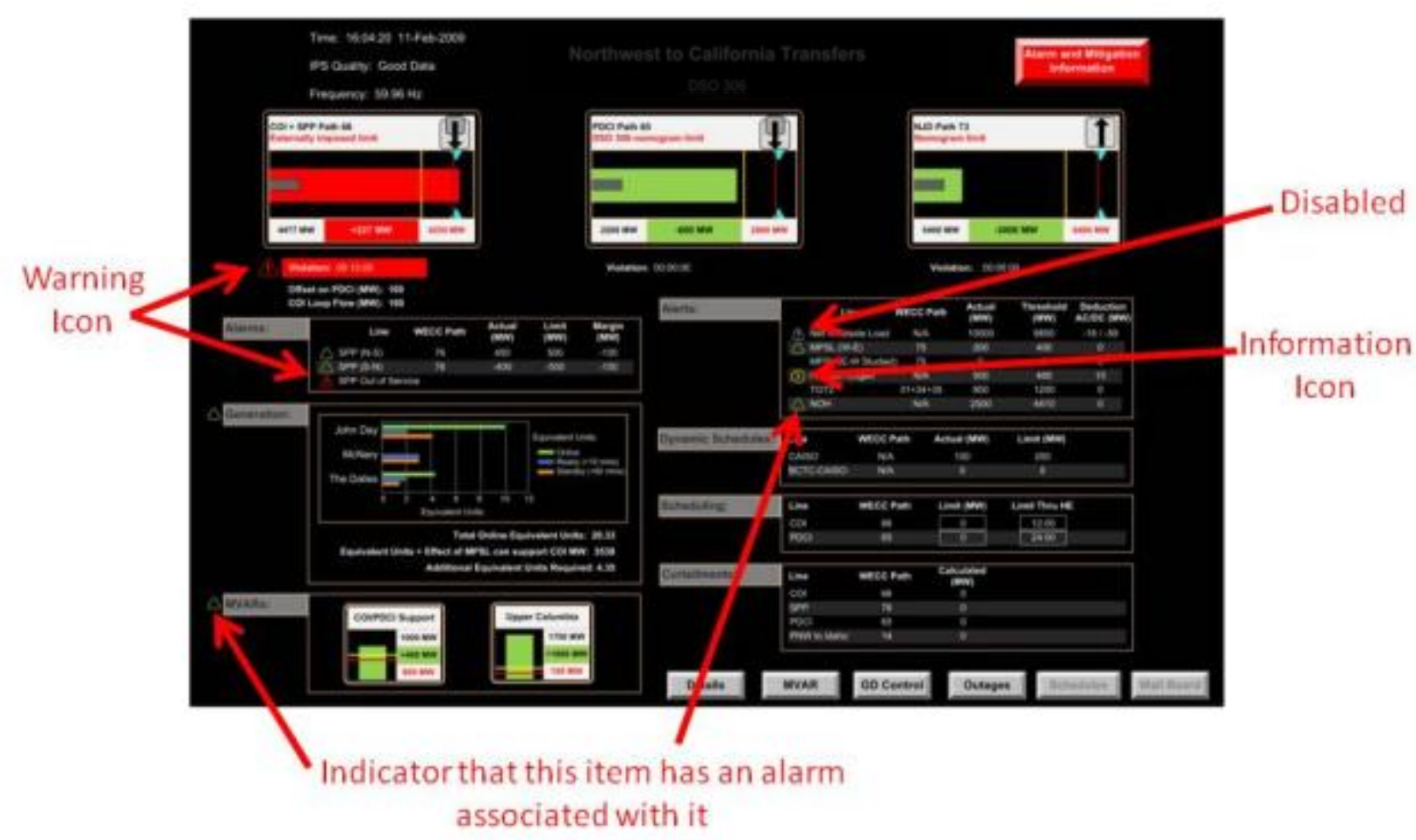

Figure 3-10. Examples of Icons.

The warning icon is a triangle with an exclamation point and can indicate 4 states of warning indicated by its color:

- Red warning icon indicates an alarm is occurring on a give path/line. It requires immediate action from the dispatcher. If the icon is blinking, then this is a new alarm; if the icon is constantly visible, the alarm has been acknowledged by the dispatcher.

- Yellow warning icon indicates an alarm may be pending on a given path/line. It requires that the dispatcher be aware of the situation.

- Green triangle indicates that all is within operating norms on a given path/line. No attention is required by dispatch. The green triangle is there to notify that a given path/line has the ability to alarm.

- Dark grey (disabled) warning icon indicates that the given path/line can potentially have an alarm but the alarm feature for the path/line has been disabled by a dispatcher.

Again, the assigned colors were kept consistent in meaning throughout the display. Red, yellow, and green are already the colors used in the bar meters to indicate the state of flow on a path/line.

In addition to the warning and information icons, the bar meters contain flow icons. CLIENT dispatchers voiced a need to understand the flow along a given path. Figure 3-11 shows all of the different flow icons that exist. North-South-East-West flow directions correspond to the direction of the arrow (up, down, right, left, respectively). Flow into or out of the utility is indicated by the start and end point of the arrow: flow into the utility is shown by an arrow that starts outside and ends inside of an inner rectangle representing CLIENT span of authority. 


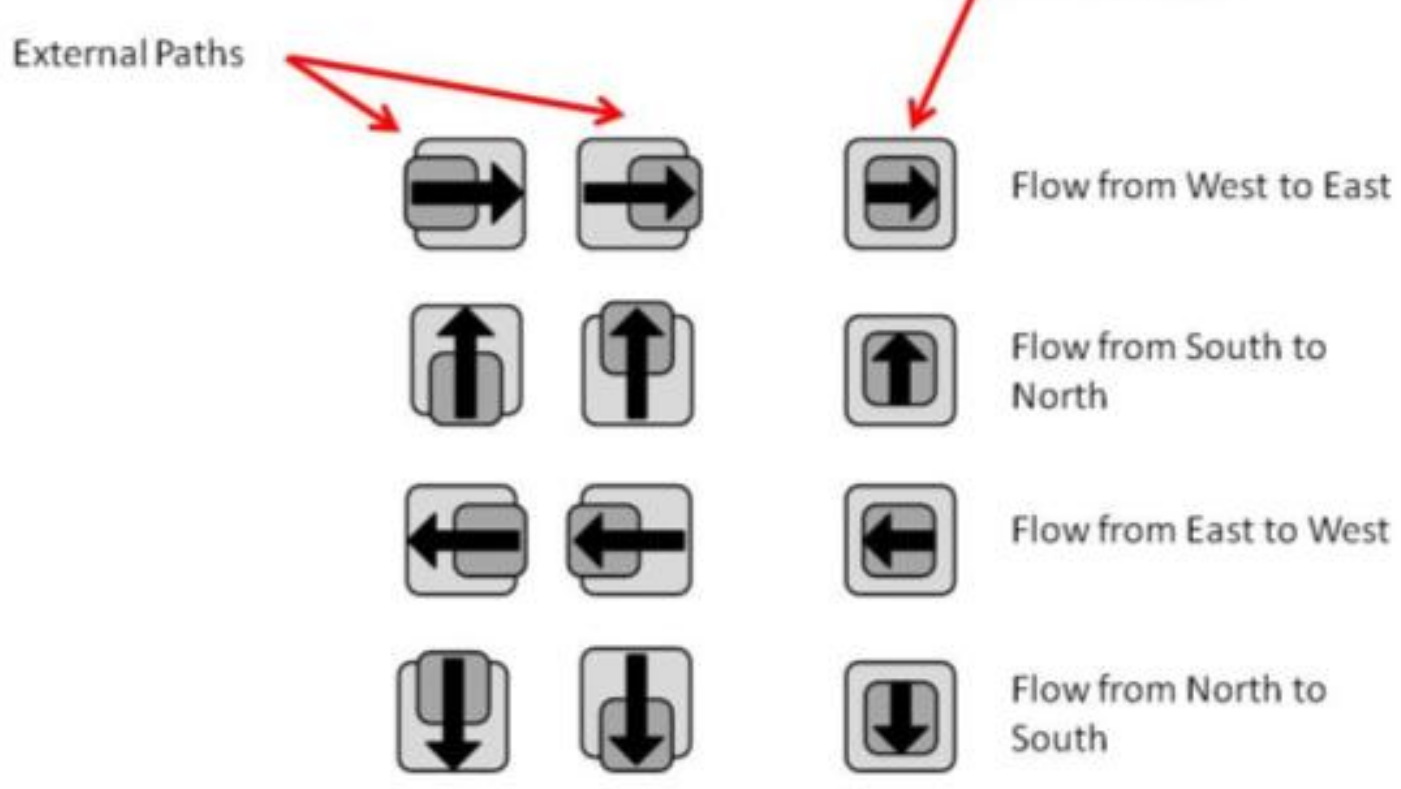

Figure 3-11. Flow Icons.

The first row of icons in Figure 4-11 indicates west to east flow; the second row of icons indicates south to north flow; the third row of icons indicates east to west flow; and the fourth row of icons indicates north to south flow. The first column of icons in Figure 3-11 indicate flow leaving the utility; the second column of icons indicates flow entering the utility; the third column of icons indicates internal flow. For example, the icon in the top row and first column indicates a flow that is leaving in a west-east direction.

\section{Bar Meters on the DSO 306 Display}

The bar meters are a dominant part of the DSO display, located at the top of the display. These bar meters are graphical representations and show the relationship between actual flow, schedule flow, OTC (limit with deductions), etc. These concepts are outlined in Figure 3-12.

The bar meter provides all information related to a path in one view. First, the path name and WECC number are visible at the top of the bar meter, allowing for easy identification and communication between authorities. If a user clicks on this area, a pop-up window appears that lists all the lines associated with this path. Under the path name is the text describing the most limiting deduction on that path. The main part of the meter is allocated to actual and schedule flows. Viewing the bar meter, dispatchers can easily determine the zone (green, yellow, red) of the actual and schedule flow, which was unavailable on the current DSO display. Also, the bar meter indicates "how far away" or "how much over" the limit the flows are; for precise actual flow values, a dispatcher can read the values under the bar meter. For precise schedule flow values, a user "hovers" the mouse over the schedule flow and a pop-up will appear with the values. 


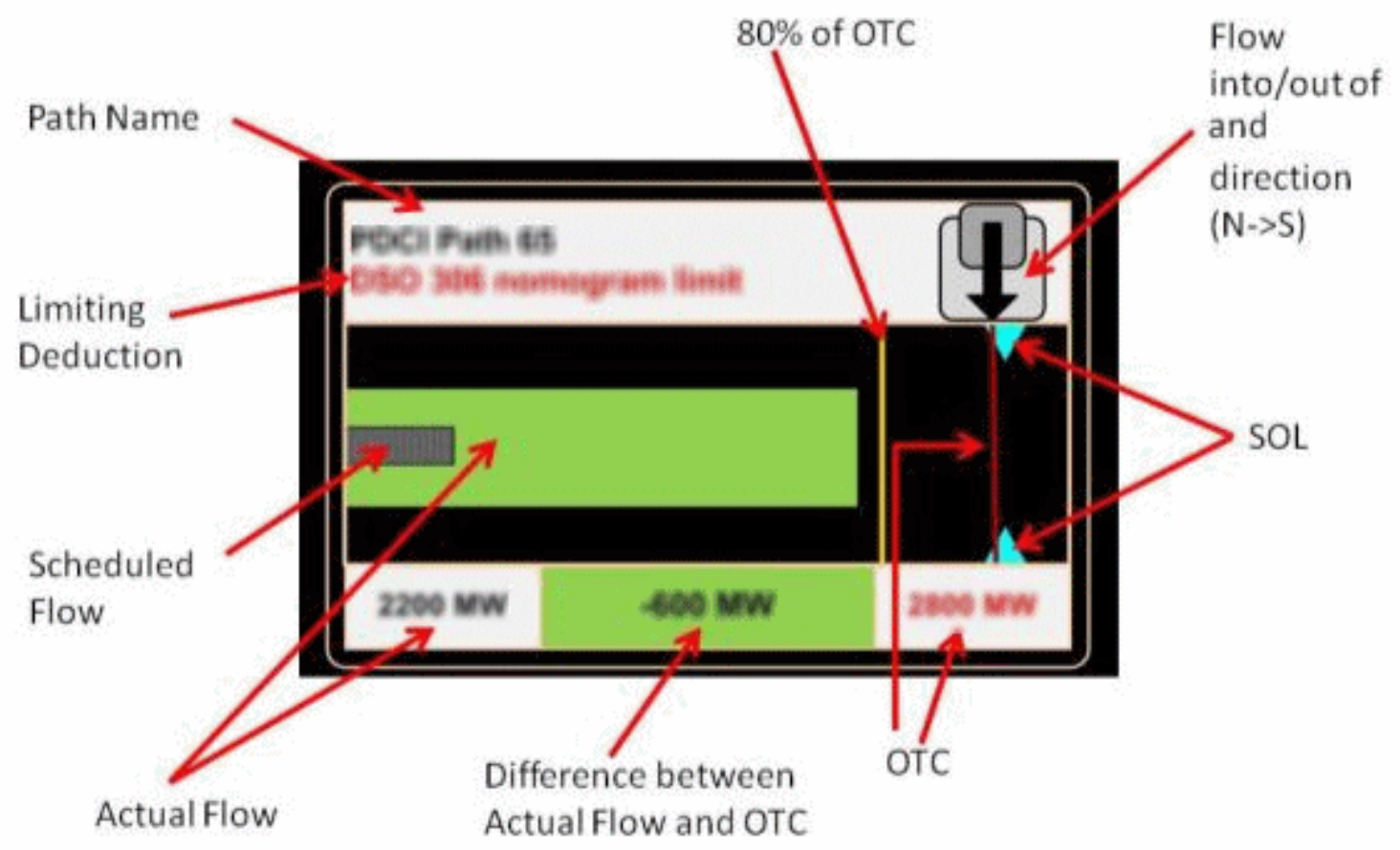

Figure 3-12. Bar Meter in Detail.

The bar meters not only display real-time values, but they also support certain interactions. For example, when a dispatcher clicks on the red OTC line or on the OTC value, this will pop-up a window listing the deductions affect the limit. An example of this is depicted in Figure 3-13. In addition, when a dispatcher clicks on the blue triangles (SOL), a pop-up will show the actual value for that path with no deductions.

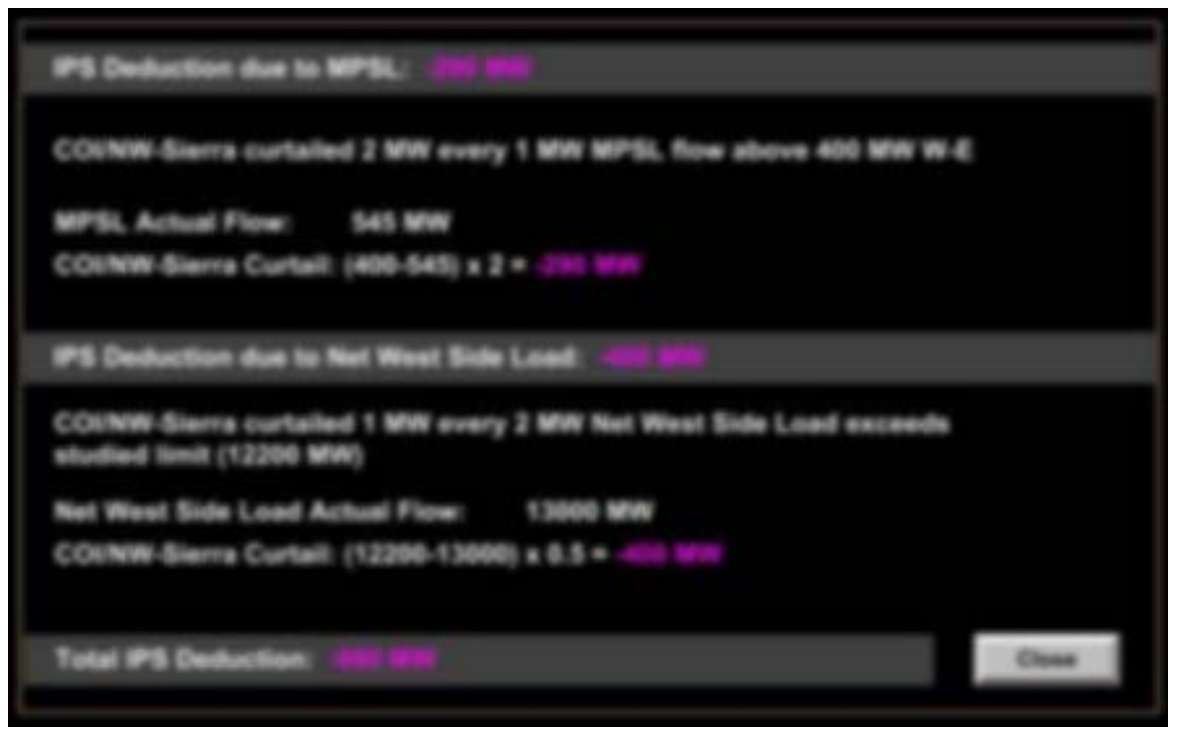

Figure 3-13. Example of a Deductions Pop-up Window. 


\subsection{Details and Calculator Displays}

\subsection{Alarm and Mitigation Information Display}

\subsection{Video Wall Board Display}

\subsection{Conclusions and Path Forward \\ [Abbreviated]}

This section outlines our summary and conclusions for the first phase of this project.

\subsection{Summary and Conclusions}

Based on the research conducted in this project and documented in this report, we have designed and developed new displays to improve dispatcher SA and effectiveness. Prototype operational versions of the new designs for the DSO 306, the Details and the Calculator displays have been implemented for use in the CLIENT control center and training center. After a period of "breaking in" enabling operators to become familiar with the new displays, it may be necessary to make some tweaks to the designs for improved usability and effectiveness based on user feedback.

The methods and displays designs employed for the selected problem translate readily to other CLIENT applications/events, and during this break-in period CLIENT may wish to use the design solutions for the selected problem as a model or standard by which to inform development of displays for other problems.

\subsection{Recommendations and Path Forward}

[Recommended actions are described in abbreviated form]

As a path forward, following is a list of recommended next steps based on needs identified to improve displays, visualizations and processes in normal and emergency power grid operations.

- Address design/implementation needs associated with the video display wall.

- Develop cost-benefit analysis for implemented design improvements

- Apply the design enhancements developed for the selected problem to other displays/events.

- Follow-up on additional display/visualization issues for the selected problem, including alarm and mitigation strategies.

- Investigate advanced decision support and visualization, focusing on predictive instead of reactive operational decision making. In contrast to developing displays to streamline response to alerts/alarms, this approach focuses on the deeper level of situation awareness that enables decision makers to more effectively anticipate and plan for problems in advance. This applied research would attempt to incorporate new/advanced solutions such as phasor state estimation, advanced geographic-based contingency analysis, and other computational and visualization approaches. 


\subsection{References}

Brown, J.R. and Cunningham, S. (1989) Programming the User Interface: Principles and Examples, Wiley.

Endsley, M. R. (1997). The role of situation awareness in naturalistic decision making (Chapter 26), in C.E. Zsambok \& G. Klein (eds.), Naturalistic Decision Making. Mahwah, NJ: Lawrence Erlbaum Associates.

Gordon, S.E., and Gill, R.T. (1997). Cognitive task analysis. In Zsombok, C. and Klein, G. (Eds). Naturalistic Decision Making. Erlbaum, Mahwah, NJ.

Greitzer, F. L., Podmore, R., Robinson, M., \& Ey, P. (2009). Naturalistic Decision Making for Power System Operators. Paper presented to the Ninth Annual Naturalistic Decision Making Conference, London, England. Also to be published in the International Journal of HumanComputer Interaction (in press).

Klein, G. A. (1993). A Recognition Primed Decision (RPD) Model of Rapid Decision Making. In G.A. Klein, J. Orasanu, R. Calderwood \& C.E. Zsambok (eds.), Decision Making in Action: Models and Methods. Norwood, NJ: Ablex Publishing.

Miller, G. A. (1956). The magical number seven plus or minus two: Some limits on our capacity to process information. Psychological Review, 63, 81-97.

Murch, G. M. (1984). Physiological principles for the effective use of color. IEEE Computer Graphics and Applications, 4(11):49-54.

Norman, D. Some Observations on Mental Models. In Mental Models, D. Genter and A. Stevens, eds. Lawrence Erlbaum Associates, 1983, pp. 7-14.

Pancake, C. M. Principles of Color Use for Software Developers. Tutorial M1 from Supercomputing '95, 1995.

Taylor, J. M., and Murch, G. M. The Effective Use of Color in Visual Displays: Text and Graphics Applications. Color Research and Applications Vol. 11 Supplement (1986), pp. S3-10. 



\section{Appendix D: Human Factors Background for Analysis and Redesign of Displays}

This appendix briefly reviews some human factors/display design concepts as background for the analysis and redesign of displays documented in this report. In addition to a general discussion of human factors and user interface display guidelines, the appendix presents current research in human factors and cognitive task analysis conducted by PNNL, with specific application to electric power grid operational decision making, that has served as a framework for the analysis conducted on CLIENT displays and visualizations. 


\section{Guidelines}

This Appendix reviews some of the human factors research that has been applied in redesigning the CLIENT displays, including guidelines and suggestions about effective use of color based on an article by Wright, Mosser-Wooley and Wooley (1997). For more information on human factors display guidelines and standards, see Laurel (1990), Nielsen (2001), Shneiderman (1993), Stone et al. (2005), Travis (1991), and Ware (2000), and the paper by Wright et al. (1997). A leading set of guidelines, offered by Nielsen (2001) includes the following general strategies for successful design of user-computer systems:

1. Visibility of system status

2. System matches real world

3. User control

4. Consistency

5. Recognize/recover from errors

6. Prevent errors

7. Recognition rather than recall

8. Flexible and efficient use

9. Simple, aesthetic design

10. Help and documentation

The following subsections review some pertinent, though not exhaustive, points that provide some motivation and rationale for design assessments and rationale for recommendations made in this report.

\section{Text and Design of User Interfaces}

Choosing the right font can make a display readable and useful. There are many choices to consider, such as availability, readability, character, and application. For screen fonts, the best choices are Arial, Veranda, Trebuche, and Georgia. The first three fonts were specifically designed for screen reading, and thus are the easiest to read on screen.

Many designers choose to use Times or Times New Roman since it is a very popular font. However, the use of Times (print font) and Times New Roman (screen version) is not recommended because of their poor on-screen legibility. The Times font was originally designed to maximize the amount of text that could be displayed in a line of print (hence letters are close together).

\section{Mental Models and the Effective Use of Color}

Whether we are aware or not, we develop mental models of our environment-representations, metaphors, or heuristics by which we conceptualize components of the environment, a task, etc. In work environments in which people are responsible for performing jobs or tasks, the ability of individuals to perform tasks and solve problems may be seen as a function of the accuracy of the mental models that a person has developed for their work (Norman, 1983). Goals of user interface design include development of user interface designs that reflect appropriate mental models of the system or tasks to facilitate learning and use the system. Proper use of color that is consistent with the user's mental model will facilitate the user's recognition and understanding of the important elements of the mental model. Wright et al. (1997) emphasize the need to apply color guidelines of simplicity, consistency, clarity, and language of color:

- Simplicity refers to the need to use colors that are easy to learn and remember (Pancake, 1995). Murch (1984) advises to keep the color scheme simple, with no more than five plus or minus two colors: Too many colors can be distracting. Selection of colors should be based on practical and intuitive associations of color with the concepts being displayed. Undue complication can occur if 
more than one concept is attached to a color-such overloading of the meanings of colors will interfere with the user's development and use of an effective mental model (Norman, 1983)..

- Consistency in the assignment and use of colors is important to the establishment of an overall intuitive consistency of the user interface design (Marcus, 1986). For example, changing the meaning of colors on different displays will lead to confusion. Marcus (1986) suggests that the spectral and perceptual order (red, green, yellow, blue) can be used to guide the order of the concepts attached to colors: red, which is first in spectral order, focuses in the foreground; green and yellow focus in the middle; and blue focuses in the background. In addition to these physiological aspects that cause different colors to appear at different depths, there are physiological factors that tend to interfere with users' recognition of colors (such as the same color appearing differently when set against different background colors) - in such cases the colors may be perceived differently, causing the meaning to be lost (Wright et al., 1997).

- Clarity in the use of color is important for usability. If colors are applied consistently and if the color of a search item is known in advance, the search time for finding the item is decreased (Pancake, 1995). Thus, interface colors should be standardized and used consistently across the application. Use of color compared to black and white displays can produce superior performance in processing time of information and for memory performance (Marcus, 1986). Effective use of color also enhances the aesthetics of the user interface and its appeal to users.

- Language of Color refers to the common and cultural usage of color (Wright et al., 1997). Such usage must be taken into consideration when designing user interfaces, particularly regarding cultural signs and symbols that may be attached to certain colors-for example, red is typically used in Western societies for alerts, yellow often is associated with warnings, and green is used to show normal status.

Following these guidelines will improve the usability of a product, and may help to reduce errors by facilitating the user's understanding and operation of the system (Marcus, 1986), but care must be taken to tailor the attributes of a user interface to particular system/environment requirements or usage. While the typical use of red/yellow/green is to indicate "error" status, use in particular application contexts may include other color mappings. For example, in electric power/control system operation displays that depict electronic circuits, the color green is used most appropriately to indicate that a circuit is open and therefore is not energized; while the color red is used to indicate a circuit is closed and energy is flowing through the circuit.

As Wright et al (1997) point out, "It is more difficult to use color effectively than it is to use it ineffectively." Effective use of color requires the use of proper combinations of colors (and their intensity levels), and taking into account the fact that certain combinations of colors can yield unintended negative effects. As noted above, certain combinations of bright red text on a blue background can create illusions of depth; and such unintended consequences can cause eye strain. Eye fatigue can result from the use of multiple pure colors or highly saturated colors in a display, which causes the human eye to refocus constantly, leading to eye fatigue. Examples of good and bad color combinations for user interfaces are shown in Table D-1 (after Brown and Cunningham, 1989; as reported in Wright et al., 1997). 
Table D-1. Color Combinations for User Interfaces (after Brown and Cunningham, 1989)

\begin{tabular}{|l|l|l|}
\hline Background & Best Colors for the Foreground & Worst Colors for the Foreground \\
\hline White & Black, Blue & Cyan, Yellow \\
\hline Black & Yellow, White & Cyan, Yellow \\
\hline Red & Black & Blue, Magenta \\
\hline Green & Black, Red & Cyan \\
\hline Blue & White, Yellow* & Black \\
\hline Cyan & Blue, Red & Green, White, Yellow \\
\hline Magenta & Black, Blue & Cyan, Green \\
\hline Yellow & Black, Blue, Red & Cyan, White \\
\hline
\end{tabular}

*The original table indicates that red is one of the "best" foreground colors for a blue background; however, because of the previously-noted negative effects of using red on blue (or blue on red) combinations, we have omitted the red entry in this row.

\section{Naturalistic Decision Making and Cognitive Task Analysis}

Here we describe a theory-based methodology to support design, evaluation, and training development for power grid operational decision making. The approach is strongly influenced by insights of Weick (1995) on sensemaking concepts that have been applied to power grid operations (Greitzer, Schur, Paget, \& Guttromson, 2008; Greitzer, Podmore, Robinson, \& Ey, 2009), and largely based on concepts of situation awareness (Endsley, 1995; 1997), recognition-primed decision making (RPD) (Klein, 1993), and metacognition (Cohen et al., 1997).

Situation Awareness has been described by Endsley (1997) using three levels of understanding:

- Level 1: perceiving critical factors in the environment

- Level 2: understanding what those factors mean, particularly when integrated together in relation to the person's goals

- Level 3: understanding what will happen in the near future.

\section{Naturalistic Decision Making and Cognitive Task Analysis}

Naturalistic Decision Making (NDM) is a perspective on decision-making that arose from studying how people use their experience to make decisions in real-world settings. The research focus is on how experienced people identify and assess the situation, make decisions and take action in dynamic, uncertain, and often fast-paced environments (Zsambok, 1997). Firefighting is a classic example. Here decisions must be made quickly in a dynamic situation. There is not enough time to identify and assess alternatives against some set of criteria, as normative decision theories might suggest. Other areas of NDM application and study include military commanders, airplane pilots and crews, corporate executives, and physicians (Zsambok, 1997). 
Recognition Primed Decision Making (RPD) is one of several models developed within the NDM paradigm to explain decision-making in this type of setting. The model proposes that decision makers draw upon their experience and ability to recognize similar situations to develop a single course of action with plans for contingencies (Klein, 1997). The theory takes historical inspiration from the study of chess players, who are thought to recognize certain board configurations as better than others, and make moves to create these configurations, rather than exhaustively evaluating alternative moves by looking ahead at the possible consequences. NDM is studied by observation of decision makers in action. Because much of the decision making process is not observable, this research uses methods of cognitive task analysis (CTA) to understand the decision makers prior knowledge and the thought process used to arrive at a course of action (Gordon, 1997).

CTA is an extension of traditional task analysis techniques to incorporate cognitive constructs. The goals of the analysis are the same as conventional task analysis: specifying the inputs, processes, and outputs associated with human behavior in systems to develop design approaches and training, and to compare alternative designs. Extension of the analytic process to the mental realm has required enhancements to the traditional observation and measurement methods of task analysis. Schraagen, Chipman \& Shalin (2000) produced an extensive review of issues and methods. Representation of the information gained from cognitive task analysis can take a variety of forms. Most of these are variants of network diagrams, flow charts, operational sequence diagrams, concept graphs and timelines. The specific application of the results determines the exact form of representation. Cognitive task analysis is often applied to retrospective analysis of activity logs or structured interviews in which researchers request that operators recall and describe specific cases/instances in which they were particularly successful at solving a problem. Greitzer et al. (2009) describe an extension and application of the RPD model to power grid operator decision making and training with implications for testing and evaluation of the effectiveness of new tools and visualizations as well as design and development of operator training.

This research demonstrates the potential advantages of applying systematic analysis methods to system design and evaluation, specifically applied to power grid operational decision making and simulation based training. Such approaches are already being applied with some success. Greitzer and colleagues at PNNL have been conducting a systematic analysis of operational tasks within the power grid operations center of a major electric power utility company in the Northwest. Cognitive task analyses and usercentered design are focused on identifying deficiencies in current user-computer interfaces (and information monitoring/decision making processes) and recommending improvements to processes, displays, and visualizations that promise to enhance situation awareness and lead to better and faster decisions. This user- and task-oriented approach contrasts with ad hoc, technology driven approaches that are more often applied by vendors of software tools and visualizations intended to improve performance.

\section{Operator Decision Model}

Figure D-1 depicts the Operator Decision Model. The shape-coding in Figure D-1 is meant to suggest the primary locus and role of each of the processes in the human information processing system. The ellipses represent the external real-world environment. The cues are part of the real world. They are also the boundary between the real world and the system operator. The cues are monitored by the system operator's five senses, primarily sight and hearing. The rectangles with rounded corners represents deliberate controlled processes carried out in working memory (WM) - these may reflect rule-based activity or analytical/knowledge-based activity depending on the decision maker's experience with the situation. The pure rectangles depict mental models that are retrieved from long-term memory (LTM). The metacognitive R/M quick test is accommodated in the initial mental simulation loop. The second mental simulation loop reflects the need for the system operator to assess and anticipate the impacts of their control actions. 


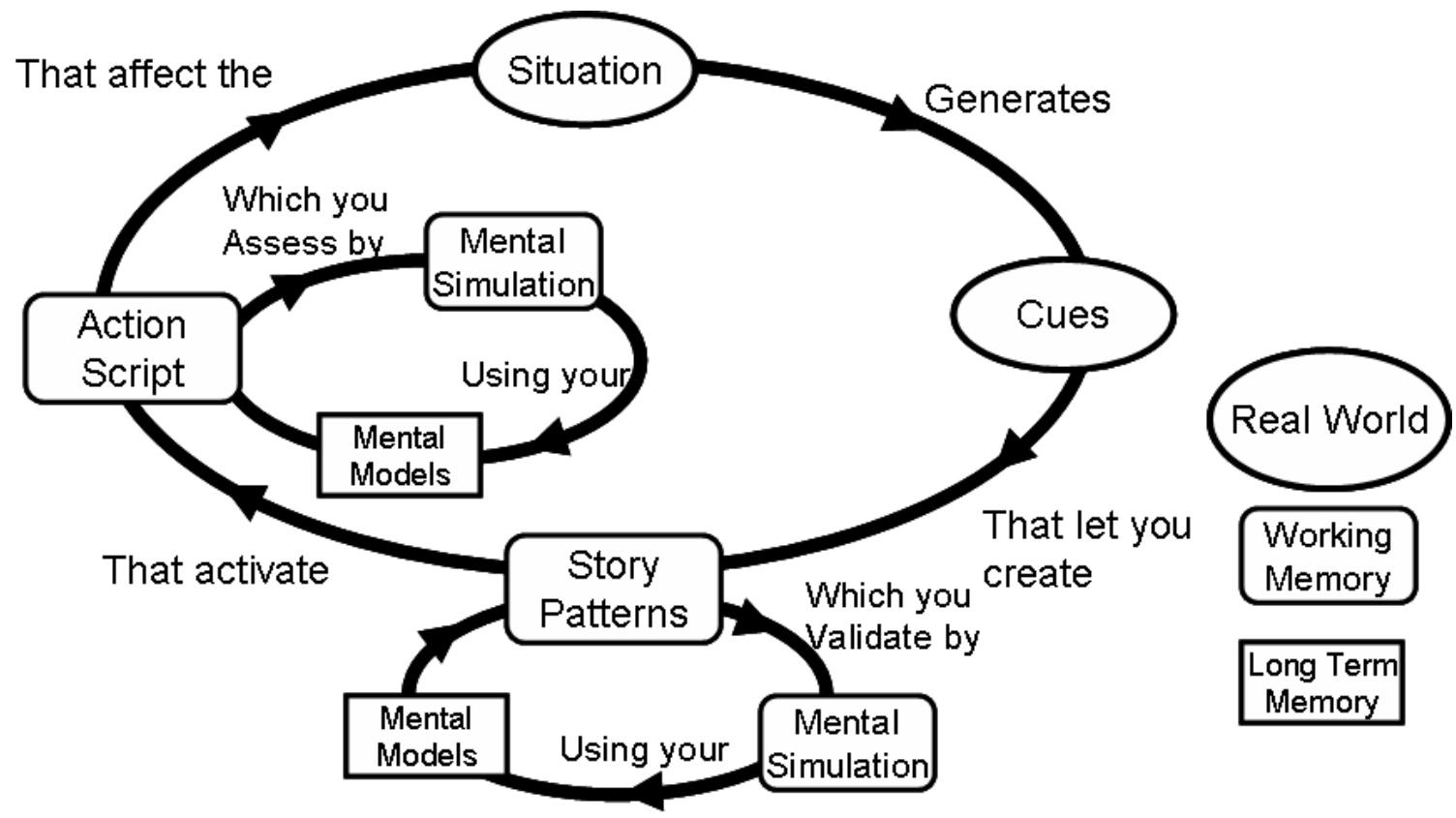

Figure D-1. Proposed Integrated Naturalistic Decision Making Model.

One can see that concepts of cues, mental models, and stories in the RPD model relate to Endsley's (1977) levels of situation awareness (SA). SA Level 1 involves the recognition of cues and patterns in the environment. More experienced operators are able to monitor a wider range of cues and patterns compared to less experienced operators. Experienced decision makers work with evolving situation models or stories. They assimilate new cues with these models as a reference, while at the same time looking for gaps and conflicts while being prepared for surprises. When an unexpected or conflicting event occurs, they elaborate the story to take it into account. They maintain an awareness of their elaborative efforts and stay alert to the danger of going too far (Cohen et al., 1997).

The initial processing of cues and patterns may be modulated by a critiquing process (using mental models and simulations) that occurs early in the recognition-primed process of situation assessment. Additional mental simulation processes occur following selection of a course of action (action script), as the decision maker examines or tests whether the proposed response action works as anticipated. The main advantage of this characterization is that it acknowledges the role of mental models in the SA component of decision making as well as in response selection.

\section{References for Appendix D}

Brown, J.R. and Cunningham, S. (1989) Programming the User Interface: Principles and Examples. Wiley.

Cohen, M. S., Freeman, J. T. \& Thompson, B. B. (1997). Training the Naturalistic Decision Maker (Chapter 25), in C.E. Zsambok \& G. Klein (eds.), Naturalistic Decision Making. Mahwah, NJ: Lawrence Erlbaum Associates. 
Endsley, M. R. (1995). Measurement of situation awareness in dynamic systems. Human Factors, 37, 32-64.

Endsley, M. R. (1997). The role of situation awareness in naturalistic decision making (Chapter 26), in C.E. Zsambok \& G. Klein (eds.), Naturalistic Decision Making. Mahwah, NJ: Lawrence Erlbaum Associates.

Gordon, S.E., and Gill, R.T. (1997). Cognitive task analysis. In Zsombok, C. and Klein, G. (Eds). Naturalistic Decision Making. Erlbaum, Mahwah, NJ.

Greitzer, F. L., Dauenhauer, P., Wierks, T. D. G., \& Podmore, R. (2009). Human Factors Evaluation of Advanced Electric Power Grid Visualization Tools. Technical Report PNNL-18386 . Richland, WA: Pacific Northwest National Laboratory.

Greitzer, F. L., Podmore, R., Robinson, M., \& Ey, P. (2009). Naturalistic Decision Making for Power System Operators. Paper presented to the Ninth Annual Naturalistic Decision Making Conference, London, England. Also to be published in the International Journal of HumanComputer Interaction (in press).

Greitzer, F. L., Schur, A., Paget, M., \& Guttromson, R. T. (2008). A sensemaking perspective on situation awareness in power grid operations. Proceedings, IEEE Power \& Energy Society Annual Meeting, 20-24 July 2008, Pittsburgh, PA. PNNL-SA-58145

Klein, G. A. (1993). A Recognition Primed Decision (RPD) Model of Rapid Decision Making. In G.A. Klein, J. Orasanu, R. Calderwood \& C.E. Zsambok (eds.), Decision Making in Action: Models and Methods. Norwood, NJ: Ablex Publishing.

Klein, G. (1997). The recognition-primed decision (RPD) model: Looking back, looking forward. In Zsombok, C. and Klein, G. (Eds). Naturalistic Decision Making. Erlbaum, Mahwah, NJ.

Laurel, B. (1990). The Art of Human-Computer Interface Design. Reading, MA: Addison-Welsey.

Marcus, A. (1986). The ten commandments of color, Computer Graphics Today, 3(10), November, 1986.

Murch, G. M. (1984). Physiological principles for the effective use of color. IEEE Computer Graphics and Applications, 4(11):49-54.

Nielsen, J. (1993). Usability Engineering. San Diego, CA: Academic Press.

Shneiderman, B. (1993). Designing the user interface: Strategies for Effective Human-Computer Interaction. Reading, MA: Addison-Wesley

Stone, D., Jarrett, C., Woodroffe, M., \& Minocha, S. (2005). User Interface Design and Evaluation. Morgan Kaufmann.

Travis, D. (1991). Effective Color Displays: Theory and Practice (Computers and People). Academic Press.

Ware, C. (2000). Information Visualization: Perception for Design. Morgan Kaufmann.

Weick, K. E. (1995), Sensemaking in organizations. Thousand Oaks, CA: Sage Publications.

Wright, P., Mosser-Wooley, D., \& Wolley, B. (1997). Techniques and tools for using color in computer interface design. The ACM Student Magazine, Crossroads, 3(3), March 1997.

Zsombok, C.E. (1997). Naturalistic decision making: Where are we now? In Zsombok, C. and Klein, G. (Eds). Naturalistic Decision Making. Erlbaum, Mahwah, NJ. 



\section{Appendix L: Report on Problem Selection}

This appendix contains the project memorandum for task 1. 


\section{Normal and Emergency Operation Visualization \\ Selection of Problem \\ February 2009}

\section{Goal}

Goal of this task is to select a representative event to be studied for the Normal and Emergency Operation Visualization project.

\section{Approach and Results}

\section{Developing Selection Criteria}

An approach was developed to identify an appropriate event/scenario for this phase of the project. The methodology was discussed with CLIENT in December 2008 and in January 2009, at which time the criteria were refined. The approach involves two steps as follows:

Step 1 - Mandatory Factors

- Assess each event/scenario based on the mandatory factors

- The event/scenario must pass all mandatory criteria before going to Step 2

Step 2 - Evaluation Factors

- Define the additional criteria for evaluation

- Assign weights to these factors

- Assess each event/scenario based on these factors

- Calculate the weighted evaluation score for each event/scenario

- Make recommendation.

\section{Mandatory Factors}

Mandatory factors are considerations that are deemed critical for a successful completion of the effort; these are generally described as feasibility criteria. The following mandatory factors were identified:

- Problem is important

- Problem can be clearly defined

- Problem can be solved within the allocated time

Possible events

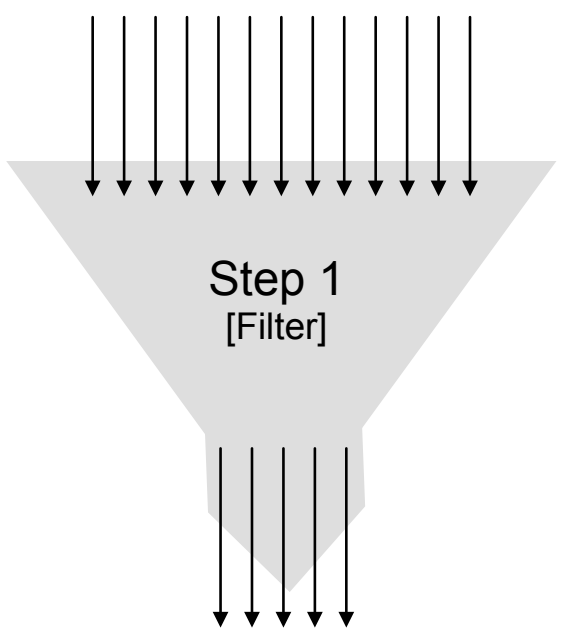

Step 2 [Weighted Analysis]

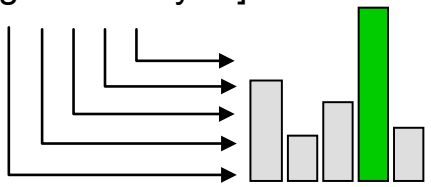

- Problem can be isolated

- EMS system has all required information (data fields) easily accessible

- Should fit with EMS/CLIENT Full Graphic system

- Staff with subject matter expertise are available

- Problem is not duplicated by other ongoing efforts. 


\section{Evaluation Factors}

Evaluation factors are used to rate candidate problems that have "passed" the mandatory/feasibility analysis. Following preparation of an initial set of evaluation factors by the STUDY TEAM, the study team discussed the factors with CLIENT dispatchers and management to arrive at a final set of evaluation criteria, as follows:

1. Frequency of occurrence (relatively frequent)

2. Potential Impact (consequence in terms of cost, down time...?)

3. Common Procedures across multiple situations

4. Common problem across utilities

5. Requires views/displays shared by multiple users

6. Multiple impacts?

7. Mitigation tool availability

To determine the relative weighting/importance of these evaluation factors, the STUDY TEAM asked the CLIENT dispatchers to identify how important each of these seven factors are in selecting a problem for the study. Each dispatcher was given ten "votes" to distribute any way they wished across the seven factors. Seven dispatchers participate in this exercise. Results of this exercise are shown below, Table 1.

Table 1. Evaluation Factors with Normalized Weights

\begin{tabular}{|c|c|c|}
\hline Evaluation Factor & $\begin{array}{l}\text { Number of } \\
\text { Votes }\end{array}$ & $\begin{array}{l}\text { Normalized } \\
\text { Weight }\end{array}$ \\
\hline 1. Frequency of occurrence (relatively frequent) & 9 & 3.0 \\
\hline $\begin{array}{l}\text { 2. Potential Impact (consequence in terms of cost, down } \\
\text { time...?) }\end{array}$ & 13 & 4.4 \\
\hline 3. Common Procedures across multiple situations & 10 & 3.4 \\
\hline 4. Common problem across utilities & 1 & 0.3 \\
\hline 5. Requires views/displays shared by multiple users & 15 & 5.0 \\
\hline 6. Multiple impacts? & 11 & 3.7 \\
\hline 7. Mitigation tool availability & 11 & 3.7 \\
\hline
\end{tabular}

The second column shows the number of votes for each factor. ${ }^{6}$ The third column shows the weightings determined for each of the factors, where the factor with the highest weight was assigned a value of 5.

\section{Identifying Potential Problems for Study}

An initial set of potential problems or "events" was developed for consideration as study topics:

- Alarms visualization

- Contingency analysis results

- Overview of system states

- Voltage profile

- Line overloads

- System Restoration

- Interchange Scheduling

- Breaker failure

${ }^{6}$ Only 69 "votes" were tallied; one of the raters apparently only used nine votes. For the remaining calculations, the missing vote was arbitrarily assigned to factor \#4, which did not receive any votes. This does not affect the results of the analysis. 
- Impact of loss of element on a SPECIFIED PATH

- Single element outage

- Performance indicator

As part of the Step 1 (mandatory factors) analysis, some of the above events were eliminated. In particular, contingency analysis was eliminated because it is addressed by a different project. The interchange scheduling problem was not considered to be sufficiently significant or important, so it was eliminated from the list. The remaining candidate problems were grouped into four major categories as follows:

1. Impact of single/multiple element outage on multiple paths

o Impact of loss of element on SPECIFIED PATH

o Breaker failure

o Outage outside of balancing area impacting CLIENT

2. Alarms visualization

o RAS action

3. System Restoration

o Island identification

4. Normal Ops/Health analysis overview map (e.g., using PMU/voltage oscillation data)

o Voltage sensitivity

o Voltage profile

o Line overloads

o Surge impedance load monitor

o Monitoring oscillation

\section{Rating the Candidate Problems on the Evaluation Criteria}

At the next stage of the process, the CLIENT dispatchers were asked to rate the four candidate problems along each of the seven evaluation factors. For each evaluation factor, a problem was given an importance rating between LOW and HIGH. Ratings in-between were allowed, e.g., a problem could be rated as "H/M" to indicate that it was considered high to moderate importance.

The results of this rating exercise are shown in Table 2.

Table 2. Ratings of Four Candidate Problems on Each Evaluation Factor

\begin{tabular}{|l|l|l|l|l|}
\hline Evaluation Factor & $\# 1$ & $\# 2$ & $\# 3$ & $\# 4$ \\
\hline Frequency of occurrence (relatively frequent) & $\mathrm{H} / \mathrm{M}$ & $\mathrm{H}$ & $\mathrm{L}$ & $\mathrm{H}$ \\
\hline $\begin{array}{l}\text { Potential Impact (consequence in terms of cost, down } \\
\text { time...?) }\end{array}$ & $\mathrm{H} / \mathrm{M}$ & $\mathrm{M} / \mathrm{L}$ & $\mathrm{H}$ & $\mathrm{H}$ \\
\hline Common Procedures across multiple situations & $\mathrm{H}$ & $\mathrm{H}$ & $\mathrm{H}$ & $\mathrm{H}$ \\
\hline Common problem across utilities & $\mathrm{H}$ & $\mathrm{L}$ & $\mathrm{H}$ & $\mathrm{H}$ \\
\hline Requires views/displays shared by multiple users & $\mathrm{H}$ & $\mathrm{L}$ & $\mathrm{H}$ & $\mathrm{H}$ \\
\hline Multiple impacts? & $\mathrm{H}$ & $\mathrm{L}$ & $\mathrm{H}$ & $\mathrm{H}$ \\
\hline Mitigation tool availability & $\mathrm{H}$ & $\mathrm{L}$ & $\mathrm{M}$ & $\mathrm{H}$ \\
\hline
\end{tabular}

\section{Analysis}

For purposes of analysis, the following values were assigned to the importance ratings: $\mathrm{H}=5, \mathrm{H} / \mathrm{M}=4, \mathrm{M}=3, \mathrm{M} / \mathrm{L}=2, \mathrm{~L}=1$. 
Using the weights for each of the evaluation factors and the importance ratings above, the overall weighted judgments of the four candidate problems may be determined by summing the weighted values. $^{7}$

The analysis is summarized in Table 3 . The evaluation factor weights $w_{j}$ (for $j=1$ to 7 ) and the numeric ratings $\mathrm{R}_{\mathrm{ij}}$ (for $i=1$ to $4, j=1$ to 7 ) of each of the candidate problems are shown in the table, along with the computed weighted "utility" score $\mathrm{U}_{i}$ for each of the four problems, where

$$
\mathrm{U}_{i}=\sum_{j} w_{\mathrm{j}} \times \mathrm{R}_{i j} \quad \text { for problem } i \text {. }
$$

In the last row of the table, the overall utility scores are translated into a percentage of the maximum possible score, using

$$
\text { Aggregate } \% \text { of Max. Possible Score }_{(i)}=100 \times U_{i} /\left(5 \sum_{j} w_{j}\right)
$$

Table 3. Evaluation Results

\begin{tabular}{|l|c|l|l|l|l|}
\hline Evaluation Factor & Weight & $\mathbf{\# 1}$ & $\mathbf{\# 2}$ & $\mathbf{\# 3}$ & $\mathbf{\# 4}$ \\
\hline Frequency of occurrence (relatively frequent) & 3.0 & 4 & 5 & 1 & 5 \\
\hline Potential Impact (consequence in terms of cost, down time...?) & 4.4 & 4 & 2 & 5 & 5 \\
\hline Common Procedures across multiple situations & 3.4 & 5 & 5 & 5 & 5 \\
\hline Common problem across utilities & 0.3 & 5 & 1 & 5 & 5 \\
\hline Requires views/displays shared by multiple users & 5.0 & 5 & 1 & 5 & 5 \\
\hline Multiple impacts? & 3.7 & 5 & 1 & 5 & 5 \\
\hline Mitigation tool availability & 3.7 & 5 & 1 & 3 & 5 \\
\hline WEIGHTED SCORE & & $\mathbf{1 1 0 . 1}$ & $\mathbf{5 3 . 4}$ & $\mathbf{9 8 . 0}$ & $\mathbf{1 1 7 . 5}$ \\
\hline Aggregate \% of Maximum Possible Score & & $\mathbf{9 4 \%}$ & $\mathbf{4 6 \%}$ & $\mathbf{8 3 \%}$ & $\mathbf{1 0 0 \%}$ \\
\hline
\end{tabular}

The results of this analysis show that Problem 4 (Normal Ops/Health analysis overview) received the highest recommendation followed closely by Problem 1 (Impact of single/multiple element outage on multiple paths).

\section{Summary and Discussion}

The analysis shows that Problem 4 is slightly preferred to Problem 1 as a candidate for this study. Upon further discussion about these two problems, it was strongly agreed that Problem 4 presents a much greater challenge than originally considered. That is, there was serious question as to whether Problem 4 could be addressed satisfactorily within the timeframe and scope of the first phase of the project. It was also generally considered that solving Problem 1 would be more feasible — and would facilitate the ability to address Problem 4 in a future phase.

\footnotetext{
${ }^{7}$ This is a standard analytical decision method that calculates subjective expected utility functions.
} 
Therefore, the overall recommendation is to select Problem 1 (Impact of single/multiple element outage on multiple paths) as the general focus of the current study. To further refine the problem within a practical scope, it is recommended that the study focus initially on Impact of loss of element on SPECIFIED PATH. This is a critical issue by itself. When solving this problem, the approach will be to generalize as much as possible in order to apply the analysis and results to the broader Problem \#1, Impact of single/multiple element outage on multiple paths.

It was also recommended that after the results are obtained for Problem 1, a second-phase effort could expand the analysis to multiple paths, and a third phase effort could address Problem 4, Normal Ops/Health analysis overview. 